LBNL-63804

MICE Note-195

\title{
AC Losses in the MICE Channel Magnets Is This a Curse or a Blessing?
}

\author{
M. A. Green ${ }^{a}$, H. Wu ${ }^{b}$, L. Wang ${ }^{b}$ L. L. Kai ${ }^{b}$, L. X. Jia ${ }^{b}$, and S. Q. Yang \\ a) Lawrence Berkeley National Laboratory, Berkeley CA 94720, USA \\ b) Institute of Cryogenics and Superconductive Technology, HIT, Harbin, China \\ c) Oxford University Physics Department, Oxford OX1-3RH, UK
}

31 January 2008*

\begin{abstract}
This report discusses the AC losses in the MICE channel magnets during magnet charging and discharging. This report talks about the three types of $\mathrm{AC}$ losses in the MICE magnets; the hysteretic AC loss in the superconductor, the coupling AC loss in the superconductor and the eddy current AC loss in the magnet mandrel and support structure. AC losses increase the heat load at $4 \mathrm{~K}$. The added heat load increases the temperature of the second stage of the cooler. In addition, AC loss contributes to the temperature rise between the second stage cold head and the high field point of the magnet, which is usually close to the magnet hot spot. These are the curses of AC loss in the MICE magnet that can limit the rate at which the magnet can be charge or discharged. If one is willing to allow some of the helium that is around the magnet to boil away during a magnet charge or discharge, $\mathrm{AC}$ losses can become a blessing. The boil off helium from the AC losses can be used to cool the upper end of the HTS leads and the surrounding shield. The AC losses are presented for all three types of MICE magnets. The AC loss temperature drops within the coupling magnet are presented as an example of how both the curse and blessing of the AC losses can be combined.
\end{abstract}

\section{TABLE OF CONTENTS}

$\begin{array}{lc}\text { Abstract } & 1 . \\ \text { Introduction } & 2 . \\ \text { Calculation of AC Losses in a Superconducting Magnet } & 3 . \\ \text { The Calculated AC Losses for the Three Types of MICE magnets } & 9 . \\ \text { The Rapid Discharge Resistor and its Effect on AC Loss } & 15 . \\ \text { Heat Leak down Conduction Cooled Leads } & 17 . \\ \text { Cooling the Top of the HTS Leads Using the Helium Boil Off Gas } & 20 . \\ \text { AC Losses and Temperature Distribution in the MICE Coupling Magnet } & 23 . \\ \text { AC Losses and Temperature Distribution in the Other MICE Magnets } & 27 . \\ \text { Some Concluding Comments } & 31 . \\ \text { Acknowledgements } & 32 . \\ \text { References } & 33 .\end{array}$

* Last revision 2 February 2008 


\section{Introduction}

AC losses were not considered when the MICE magnets were originally designed. The reason for this is that the MICE magnets are DC magnets that operate at a constant current for long periods of time [1], [2]. A second factor was that there was to be plenty of available refrigeration for cooling the magnets while they were being charged or discharged, because they were to be operated off of a large helium refrigerator [3]. A preliminary assessment of the AC Losses in the MICE focusing and Coupling magnets was made in 2004 [4]. The primary reason for doing this calculation was to determine what affect $\mathrm{AC}$ losses would have on the temperature distribution within the cold mass as the magnets were being charged. No AC loss calculations were done on the tracker magnet. The AC losses were not considered when looking at how the magnets might operate while they are being cooled using one or more small coolers [5].

AC loss energy while charging or discharging a MICE magnet basically is only put into the second stage of the cooler. If the magnet shield system is well designed, the AC losses in the first stage of the cooler are small compared to heat leaks down the copper leads, radiation heat leaks through the MLI, cold mass support heat leaks, or heat leaks down the neck tubes. Magnet AC losses will raise the second stage temperature of the cooler, because the heat is put there. For the PT-415 pulse tube cooler, proposed for the MICE magnets, the combined heat load between the heat leaks into the magnet and the AC losses cannot exceed about $2.3 \mathrm{~W}$ per cooler. When a PT-415 cooler has $2.3 \mathrm{~W}$ of heat entering the second stage, the second stage temperature is between 4.9 and $5.0 \mathrm{~K}$ [6]. (A 1.5 watt GM cooler would behave exactly the same way as a $1.5 \mathrm{~W}$ pulse tube cooler, so this is not a cooler issue.) At temperatures approaching $5 \mathrm{~K}$, the thermal-siphon flow system ceases to operate, because the helium circuit pressure is close to the critical pressure for helium. (The density difference between liquid and gas is small.) When the helium system pressure is above the critical pressure, the magnet becomes disconnected from the cooler second-stage. Thus the charge and discharge rate for the MICE magnets is limited by the cooler capacity, unless helium is boiled away and vented from the helium reservoir around the magnet at a pressure below the critical pressure.

Venting the magnet reservoir during charging or discharging is not necessarily a bad thing as long as the sensible enthalpy of the helium is used to cool the upper end of the HTS leads and the shield. Venting magnet at say $4.5 \mathrm{~K}$ (at a helium circuit pressure of $0.13 \mathrm{MPa}$ ) limits the maximum temperature in the magnet to the bath temperature plus the $\Delta \mathrm{T}$ between the hot spot in the coil package and the cooler second-stage. The vent pressure during charging and discharging can be set by looking at the magnet temperature margin. The helium that is lost from the magnet charging and discharging can be reliquefied using the cooler, provided one has time to do the re-liquefaction [7].

The AC loss curse is that AC losses will either limit the rate of charging or discharging of the MICE magnets or it will require that liquid helium be boiled away during charging or discharging process. The AC loss blessing is that the sensible heat from the helium boil off gas can be used to cool the upper end of the HTS leads and the magnet shield. Much less added mass in the shield (if any at all) is needed to keep the HTS leads cold during a rapid discharge or when there is a power failure in the MICE hall [8]. Protection of the magnet HTS leads becomes much easier as long the boil off helium is employed to cool the upper end of the HTS leads. During normal DC operation of the magnet, the cooler keeps the up end of the leads cold and no helium is boiled and vented. 


\section{Calculation of AC Losses in a Superconducting Magnet}

$\mathrm{AC}$ losses in the MICE magnet cold mass come from three sources. The first source is hysteretic AC loss, where the loss per cycle is independent of the $\mathrm{dB} / \mathrm{dt}$ in the magnet superconductor or the mandrel and support structure. The second source is coupling loss between filaments in a multi-filament superconductor. Coupling loss is caused by coupling currents between the superconductor filaments. The AC loss per cycle is proportional to $\mathrm{dB} / \mathrm{dt}$. Because the charge and discharge times in the MICE magnets are relatively long compared to the coupling current time constant, the coupling AC loss is expected to be low compared to the hysteretic AC loss. The third source of AC loss is due to coupled currents in the magnet mandrel and support structure due to coupling between the superconducting coil and the mandrel and support structure. The loss per cycle is proportional to $\mathrm{di} / \mathrm{dt}$ in the coil. During charging, the mandrel and support structure AC losses are expected to be quite small compared to the hysteretic AC losses. During a rapid discharge of any of the MICE magnets the mandrel and support structure $\mathrm{AC}$ losses can be expect to be up to 15 times larger than during magnet charging.

\section{a) Hysteretic AC Loss in a Magnet}

The largest source of AC loss heating within the coil is the hysteretic AC losses in the superconductor. Since the charge times for the MICE coils are long (>1800 s), the form of the $\mathrm{AC}$ losses in the superconductor is expected to be primarily hysteretic losses. Hysteretic loss is a function of the total induction change seen by the conductor $\Delta \mathrm{B}$, the critical current density of the superconductor $\mathrm{J}_{\mathrm{c}}(\mathrm{T}, \mathrm{B})$, the superconductor filament diameter and a factor which there because the filaments are round. This factor is about 0.43 . Thus the heat released when the field in the conductor changes by $\Delta \mathrm{B}$, can be stated using the following expression;

$$
\Delta H_{S C}=\frac{4}{3 \pi} j_{c} d_{f} \Delta B
$$

where $\Delta \mathrm{H}_{\mathrm{sc}}$ is the hysteretic loss in the superconductor per unit volume for an induction change $\Delta B$. $J_{c}$ is the superconductor critical current, and $d_{f}$ is the superconductor filament diameter. From equation 1 it is clear that the hysteretic loss is proportional to the filament diameter, the total flux change in the conductor, and superconductor critical current. For the MICE magnets $\Delta \mathrm{B}=3 \mathrm{~T}$. If average value of $\mathrm{j}_{\mathrm{c}}=7 \times 10^{9} \mathrm{~A} \mathrm{~m}^{-2}$ and if the MICE conductor filament diameter is $40 \mu \mathrm{m}$, the average hysteretic AC loss in the conductor over a flux change of $3 \mathrm{~T}$ is from $360 \mathrm{~kJ} \mathrm{~m}^{-3}$. If one doubles the filament diameter to $80 \mu \mathrm{m}$, from equation 1, the average hysteretic AC doubles to $720 \mathrm{~kJ} \mathrm{~m}^{-3}$.

When one applies equation 1 the hysteretic AC loss over the volume of the coil can be estimated using the following expression;

$$
\Delta H_{c}=\frac{4}{3 \pi} \alpha \frac{j_{c} d_{f}}{r+1} \Delta B
$$

where $\alpha$ is the conductor packing-factor for the coil and $r$ is the normal metal to superconductor ratio in the conductor. (For the MICE coils $\alpha=0.78$, and for the MICE conductor $r=4$.) For the MICE coils, $\Delta \mathrm{H}_{\mathrm{c}}=56$ to $112 \mathrm{~kJ} \mathrm{~m}^{-3}$ when the filament diameter is 40 and 80 microns respectively. 
The hysteretic $\mathrm{AC}$ loss energy $\mathrm{E}_{\mathrm{C}}$ while charging or discharging the coil can be calculated using the following expression;

$$
E_{C}=\frac{4}{3 \pi} \alpha \frac{j_{c} d_{f}}{r+1} \Delta B V_{C}
$$

where $\mathrm{V}_{\mathrm{C}}$ is the volume of the magnet coil.

The average hysteretic AC loss in the coil as it is being charged from zero to full field can be estimated using the following expression;

$$
Q_{G}=\frac{E_{C}}{t_{c h}}
$$

where $t_{c h}$ is the charge time for the MICE magnets.

The charge time for a coil is a function magnet self-inductance $\mathrm{L}$ and the average charging voltage. The charge time for the magnet can be estimated using the following expression;

$$
t_{c h} \approx L \frac{I_{c}}{V_{P S}-0.5 I_{c} R_{L}}
$$

where $I_{C}$ is the magnet design current $V_{P S}$ is the power supply voltage $\left(V_{P S}=10 \mathrm{~V}\right.$ for the MICE magnets); and $\mathrm{R}_{\mathrm{L}}$ is the resistance of the leads and diodes. At full current, the voltage drop across the leads is $\sim 3 \mathrm{~V}$, thus the average charging voltage $\mathrm{V}=8.5 \mathrm{~V}$.

Equation 1 has a number of assumptions: 1) The $\mathrm{j}_{\mathrm{c}}$ is constant during the flux change; 2) the $\mathrm{j}_{\mathrm{c}}$ doesn't change across the filament; and 3) the filament was fully penetrated during the charge or discharge of the magnet. In a real superconducting coil none of these assumptions really hold. The conductor $\mathrm{j}_{\mathrm{c}}$ is high at low fields and low at high fields. The $\mathrm{j}_{\mathrm{c}}$ varies across the superconductor, but the changes are usually quite small. The filaments are not fully penetrated for small changes in magnetic flux, and there are regions within a coil where there are filaments that are not fully penetrated. Given all of that, a simple equation such as given in equation can be used to make a conservative estimate of the hysteretic AC loss in a magnet, particularly if the magnet coil is divided into regions and the charge and discharge of the magnet is divided into time steps. The effects of filament penetration can be will in general reduce the AC loss hysteretic energy compared to equation 1.

The penetration induction $\mathrm{B}_{\mathrm{p}}$ for a filament can be calculated using the following expression;

$$
B_{p}=\frac{2}{\pi} \mu_{0} j_{c} d_{f}
$$

where $\mu_{0}$ is the permeability of free space. $\left(\mu_{0}=4 \pi \times 10^{-7} \mathrm{H} \mathrm{m}^{-1}\right)$

It is clear that if one wants to calculate hysteretic AC loss correctly, one has to divide the two-dimensional cross-section of the solenoid coil into small blocks and use the flux change $\Delta B_{B}$ over a small time change $\Delta t$. The conductor $j_{c}$ that must should be based on the magnetic induction at the center of the block $B_{B}$ at the midpoint time in the time step $\Delta \mathrm{t}$. The $\mathrm{j}_{\mathrm{c}}$ for a typical Nb-Ti superconductor as a function of $\mathrm{B}$ at $3.6 \mathrm{~K}, 4.2 \mathrm{~K}$ and $5.0 \mathrm{~K}$ is shown in Figure 1. Most large superconducting magnets operate within this temperature range. The conductor $\mathrm{j}_{\mathrm{c}}$ will be higher at lower temperatures. 


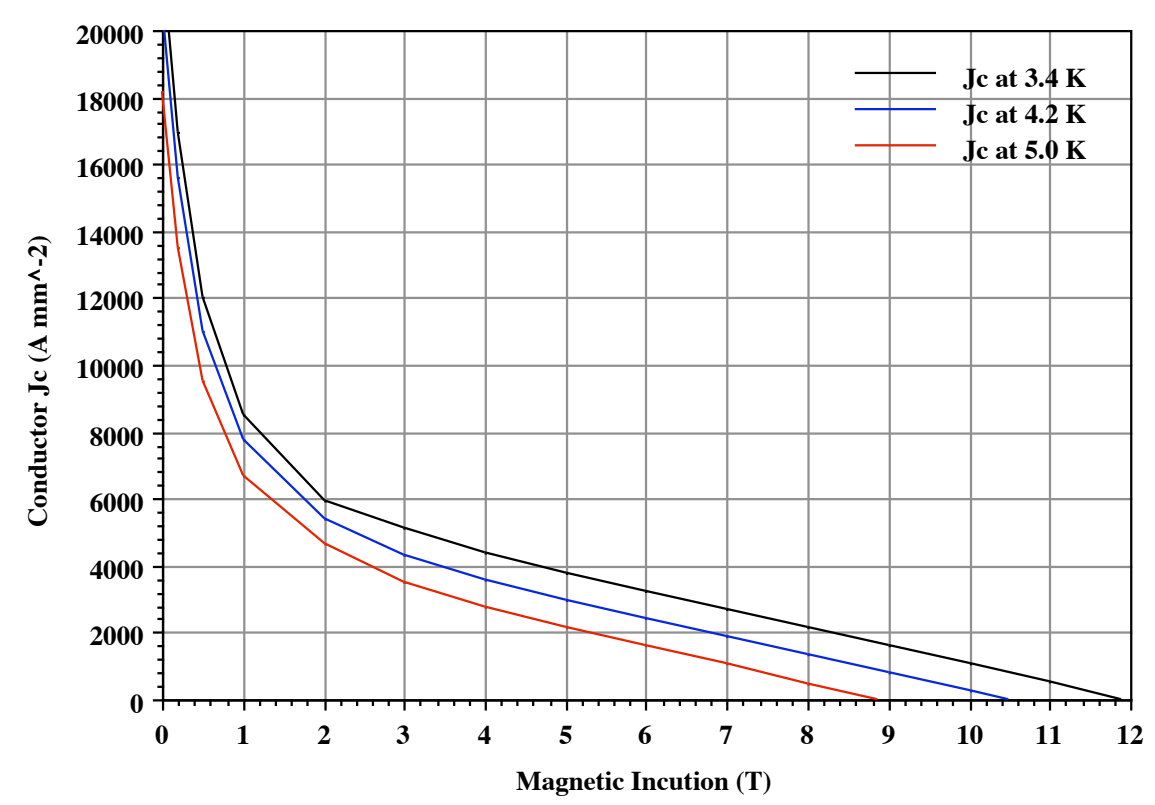

Figure 1. Typical $\mathrm{Nb}-\mathrm{Ti} \mathrm{J}_{\mathrm{c}}$ as a Function of Magnetic Induction and Temperature

Wilson [9] suggests that the AC loss can be calculated as a function of a magnetic induction function $\beta$ where $\beta=B_{B} / B_{p}$. This is somewhat complicated by the fact that $j_{c}$ varies with $B_{B}$ and therefore $B_{p}$ and $\beta$ will also vary with $B_{B}$. The AC loss per cycle (going up and back) for a change $B_{B}$ can be estimated using the following expression;

$$
Q=\frac{B_{B}{ }^{2}}{2 \mu_{0}} \Gamma(\beta)
$$

where $\Gamma(\beta)$ is the beta function shown in Figure $2 ; j_{c}\left(B_{B}\right)$ is the $j_{c}$ at induction $B_{B}$, and $\mathrm{j}_{\mathrm{c}}\left(\mathrm{B}_{\mathrm{p}}\right)$ is the $\mathrm{j}_{\mathrm{c}}$ at the penetration induction $\mathrm{B}_{\mathrm{p}}$.

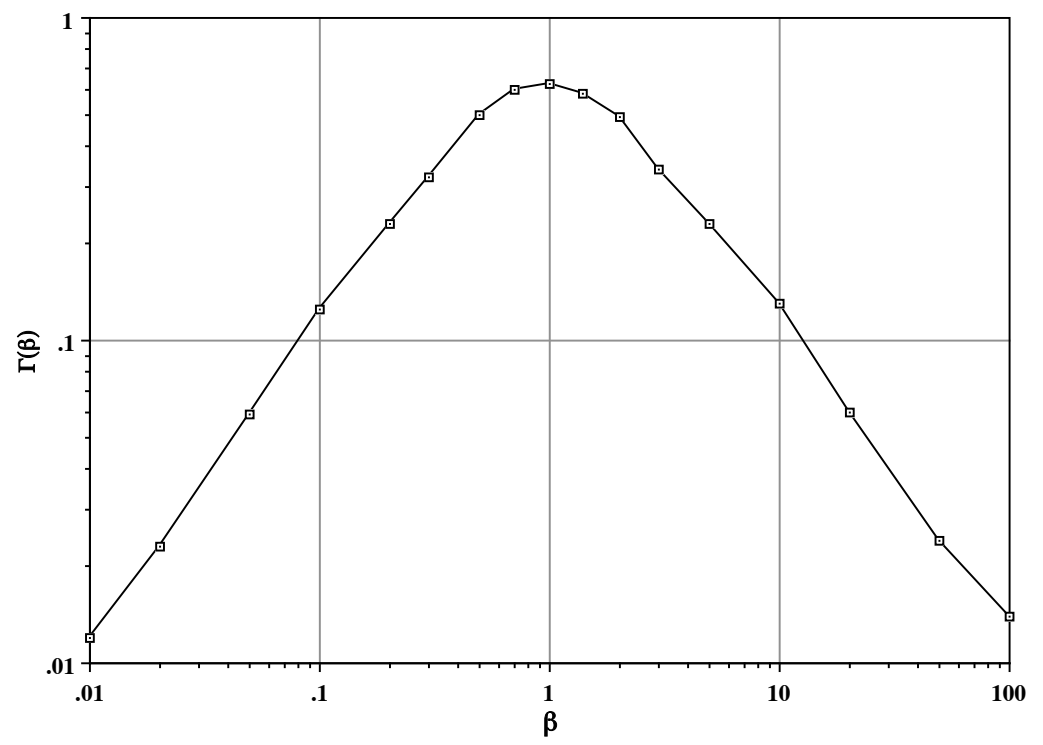

Figure 2. $\Gamma(\beta)$ as a Function of $\beta$ for Flux Transverse to the conductor (Note: $\beta=B_{B} / B_{p}$ ) 
In the limit where $\beta>>1, \Gamma(\beta)$ is $4 / 3 \beta$, and applying equation 2 , equation 3 takes the following form;

$$
\Delta H=\frac{4}{3 \pi} B_{B} j_{c}\left(B_{B}\right) d_{f},
$$

which is the same basic equation as equation 1.

To first order, a conservative estimate of the hysteretic AC loss can be made using equation 4 , provided the coil is divided into $\mathrm{N}$ regions and the charge time is divided into $\mathrm{M}$ time steps. The AC loss energy for time step $\mathrm{m}$ can be estimated as follows;

$$
\Delta H_{m}=\frac{4}{3 \pi} \sum_{n=1}^{n=N} \Delta B_{n m} j_{c}\left(B_{n m}\right) d_{f}
$$

where

$$
\Delta B_{n m}=\frac{a b s\left(B_{n M}-B_{n 0}\right)}{M}
$$

$-9 a-$

and

$$
B_{n m}=\frac{B_{n m}+B_{n(m-1)}}{2}
$$

$-9 b-$

where $B_{n 0}=0$ for all parts of the coil when the coil is charged. (This assumes the start of the coil charge is at zero current.) $\mathrm{B}_{\mathrm{nM}}=0$ for all parts of the coil when it is discharged. (This assumes that the coil current is zero at the end of the discharge.)

When one applies equation 8 the hysteretic AC loss over the volume of the coil can be estimated using the following expression for the coil energy loss;

$$
E_{C m}=\frac{4}{3 \pi} \frac{\alpha}{(r+1)} \sum_{n=1}^{n=N} \Delta B_{n m} j_{c}\left(B_{n m}\right) d_{f} V_{n}
$$

where $\alpha$ and $\mathrm{r}$ are the same as in equation 2. (For the MICE coils $\alpha=0.78$, and for the MICE conductor $r=4$.)

The average hysteretic AC loss in the coil over the time step $\Delta \mathrm{t}$ can be estimated using the following expression;

$$
Q_{G}=\frac{E_{C m}}{\Delta t}
$$

The total hysteretic AC loss energy $\mathrm{E}_{\mathrm{C}}$ that is produced when charging or discharging the coil from $\mathrm{t}=0$ to $\mathrm{t}=\mathrm{t}_{\mathrm{m}}$ can be estimated using the following expression;

$$
E_{C}=\frac{4}{3 \pi} \frac{\alpha}{(r+1)} \sum_{m=0}^{m=M} \sum_{n=0}^{n=N} \Delta B_{n m} J_{c}\left(B_{n m}\right) d_{f}
$$

The average hysteretic AC loss in the coil as it is being charged from zero to full field can be estimated using the following expression;

$$
Q_{G c}=\frac{E_{C}}{t_{c h}}
$$

where $t_{c h}$ is the charge time for the MICE magnets. 
The value $\mathrm{Q}_{\mathrm{Gc}}$ generated using equation 12 should be similar to $\mathrm{Q}_{\mathrm{G}}$ generated using equation 3 assuming that the correct average $j_{c}$ and average $\Delta B$ were chosen for equation 3. The coil hysteretic AC loss energy generated by equations 11 and 2 should be larger than the energy generated by integrating equation 6 over the entire coil volume or the entire time. When equations 3 and 12 are used to generate the coil hysteretic AC loss energy when the coil is charged and discharged, the total AC loss energy should be twice the energy calculated from either equation 3 or 12 .

If the equation 6 is integrated over the coil volume and time, the hysteretic AC loss energy generated will be larger for the discharge part of the cycle than the charging part of the cycle. The reason for this difference is that flux penetration at low field reduces the AC loss more than flux penetration at high field when the coil is discharged.

\section{b) Coupling AC Loss in a Magnet}

Coupling AC loss is caused by super-currents flowing along the filaments with each filament carrying $\mathrm{j}_{\mathrm{c}}$. The super-current is driven by voltage loops between the filaments. The coupling super-currents are reduced by transposing (or twisting) the superconductor within the conductive matrix in which the filaments are extruded and drawn.

The AC loss per unit volume of the superconductor can be calculated using the following expression;

$$
P=\frac{2}{\mu_{0}}\left[\frac{d B}{d t}\right]^{2} \tau
$$

where $\mathrm{dB} / \mathrm{dt}$ is the rate of flux change in the conductor; $\mu_{0}=4 \pi \times 10^{-7} \mathrm{H} \mathrm{m}^{-1}$; and $\tau$ is the coupling current time constant for the conductor.

The coupling current time constant $\tau$ can be calculated using the following expression;

$$
\tau=\frac{\mu_{0}}{2 \rho_{e t}}\left[\frac{L}{2 \pi}\right]^{2}
$$

where $\rho_{\mathrm{et}}$ is the effective resistivity between the superconducting filaments and $\mathrm{L}$ is the transposition pitch (or twist pitch) of the filaments within the conductor matrix. The value of $\rho_{\text {et }}$ can be calculated using the following expression;

$$
\frac{1}{\rho_{e t}}=\frac{1}{\rho_{t}}+\frac{2 w}{d_{f} \rho_{m}}+\frac{d_{f} w}{\rho_{m}}\left[\frac{2 \pi}{L}\right]^{2}
$$

where $\rho_{\text {et }}$ is the effective transverse resistivity; $\rho_{\mathrm{t}}=\rho_{\mathrm{m}}(1+\lambda) /(1-\lambda) ; \rho_{\mathrm{m}}$ is the matrix resistivity at the local magnetic field; $\lambda=1 /(\mathrm{r}+1)$; $\mathrm{d}_{\mathrm{f}}$ is the filament diameter; $\mathrm{w}$ is the copper thickness outside the filament bundle. For MICE conductor $\rho_{\mathrm{m}}=3 \times 10^{-10} \mathrm{ohm} \mathrm{m}$, $\mathrm{r}=4, \mathrm{~d}_{\mathrm{f}}=41 \times 10^{-6} \mathrm{~m}, \mathrm{w}=240 \times 10^{-6} \mathrm{~m}$, and $\mathrm{L}=0.019 \mathrm{~m}$, thus $\rho_{\mathrm{et}}=1.299 \times 10^{-11} \mathrm{ohm} \mathrm{m}$. The coupling current $\tau=0.442 \mathrm{sec}$, which is short compared to the charge time.

If the charge time for a typical magnet is 3000 seconds and $\Delta \mathrm{B}$ in the coil is $3 \mathrm{~T}$, the value of $\mathrm{dB} / \mathrm{dt}$ during charging is $0.001 \mathrm{~T} \mathrm{~s}^{-1}$. When one applies equation 14 , one finds that the coupling AC loss per unit conductor volume is about $0.703 \mathrm{~W} \mathrm{~m}^{-3}$, which is much lower than the hysteretic AC loss for the same conductor. (See the calculations using equation1.) For all practical purposes, coupling loss can be neglected for the MICE coils. 


\section{c) Mandrel and Coil Structure AC Losses}

The AC losses in the mandrel caused by current induced in the mandrel by the di/dt when the coil adjacent to the mandrel (and support structure) is charged and discharged. The coil inductance $L_{1}$ is a function of its geometry and the number of turns in the coil. If one knows the coil inductance, one can make a guess at the inductance of the mandrel. To first order the mandrel inductance $\mathrm{L}_{2}$ can be estimated with the following expression;

$$
L_{2} \approx \frac{L_{1}}{\left(N_{1}\right)^{2}}
$$

where $\mathrm{N}_{1}$ is number of turns in the coil. It is assumed that the mandrel is a single turn coil where $\mathrm{N}_{2}=1$.

The mutual inductance between the coil and the mandrel $\mathrm{M}_{12}$ can be estimated using the following expression;

$$
M_{12} \approx \varepsilon^{0.5} \frac{L_{1}}{N_{1}}
$$

where $\varepsilon$ is the coupling coefficient between the MICE coils and their mandrels and support structure. Holger Witte at Oxford University estimated that $\varepsilon$ for the focusing magnet was about 0.8 and $\varepsilon$ for the coupling magnet was about 0.9 . The coupling coefficient for the tracker is estimated to be about 0.85 .

From the mutual inductance between the coil and the mandrel, one can estimate the voltage $\mathrm{V}_{2}$ around the mandrel. An expression for $\mathrm{V}_{2}$ is as follows;

$$
V_{2} \approx \varepsilon^{0.5} \frac{L_{1}}{N_{1}} V_{1}
$$

where $\mathrm{V}_{1}$ is the voltage put across the coil during a charge or a discharge of the coil.

The resistance of the mandrel circuit can be expressed as follows;

$$
R_{2} \approx \rho_{2} \frac{\pi D_{1}}{A_{c 2}}
$$

where $\rho_{2}$ is the resistivity of the mandrel material $\left(\rho_{2}=1.6 \times 10^{-8} \mathrm{ohm} \mathrm{m}\right.$ for 6061-T6 aluminum at $4 \mathrm{~K}$ ); $\mathrm{D}_{1}$ is the average diameter of the superconducting solenoid; and $\mathrm{A}_{\mathrm{c} 2}$ is the cross-section area of the mandrel and support structure.

The AC loss power in the mandrel and support structure can be estimated using the following expression;

$$
P_{2}=\frac{V_{2}^{2}}{R_{2}}=\frac{\varepsilon L_{1}^{2} V_{1}^{2}}{N_{1}{ }^{2}} \frac{A_{c 2}}{\rho_{2} \pi D_{1}}
$$

The AC loss power is proportional to the charging or discharging voltage squared and inversely proportional to the number of turns in the coil squared times the mandrel resistivity. To calculate the AC loss per unit volume in the mandrel divide $P_{2}$ by $\pi D_{1} A_{c 2}$.

During a full voltage charge or discharge the mandrel AC losses are quite low $(0.02$ to $0.05 \mathrm{~W}$ ) compared to the hysteretic AC losses or the capacity of the cooler. During a rapid discharge (up to $35 \mathrm{~V}$ across the power supply), the mandrel $\mathrm{AC}$ loss can go up over an order of magnitude (up to $1.5 \mathrm{~W}$ ) depending on the magnet. 


\section{The Calculated AC Losses for the Three Types of MICE magnets}

The AC losses were estimated for the coupling solenoid and focusing solenoid in 2004. (See reference 4.) More detailed calculations were done of the coupling solenoid AC losses in Harbin in April 2007. From the calculated AC losses for the coupling solenoid are based on a conductor with 41-micron filaments (the same conductor as used for the tracker magnet). If the conductor has 78-micron filaments, the hysteretic AC losses would be 1.9 times higher. Table 1 compares the basic parameters for the three types of MICE solenoids.

Table 1. The Basic Magnet Parameters for the Three Types of MICE Magnets

\begin{tabular}{|c|c|c|c|}
\hline Parameter & Coupling & Focusing & Tracker \\
\hline Coil Inner Radius (mm) & 750 & 263 & 258 \\
\hline Maximum Coil Thickness (mm) & 102.5 & 84 & 68.2 \\
\hline Total Coil Length (mm) & 285 & 420 & 1932 \\
\hline Number of Turns per Magnet & 15936 & 3332 & 31840 \\
\hline Magnet Coil Volume $\left(\mathrm{m}^{3}\right)$ & 0.1471 & 0.0676 & 0.0997 \\
\hline Magnet Current $(\mathrm{A})^{*}$ & 210.8 & 250.8 & 269.9 \\
\hline Circuit Self Inductance $(\mathrm{H})$ & 592.5 & 295.8 & $\sim 154.0$ \\
\hline Peak Induction in Coil $(\mathrm{T})^{*}$ & 7.44 & 7.67 & $\sim 5.2$ \\
\hline 4.2 K Temp. Margin $(\mathrm{K})^{*}$ & $\sim 0.8$ & $\sim 0.6$ & $\sim 1.5$ \\
\hline Number of Magnets in Circuit & 1 & 3 & 2 \\
\hline Circuit Stored Energy $(\mathrm{MJ}) *$ & 13.2 & 9.3 & $\sim 5.6$ \\
\hline Charging Voltage per Magnet (V) & 9.0 & 3.0 & 4.5 \\
\hline Magnet Charging Time (s) & 13860 & 7520 & 4620 \\
\hline PS Rapid Discharge Voltage (V) & 22.1 & 20.6 & 23.1 \\
\hline Magnet Rapid Discharge Time (s) & 5400 & 3600 & 1800 \\
\hline Average Field in the Coil $(\mathrm{T})^{*}$ & $\sim 3.9$ & $\sim 4.0$ & $\sim 2.5$ \\
\hline Number of Coil Regions & 5 & 3 & 2 \\
\hline Average Conductor $\mathrm{J}_{\mathrm{c}}\left(\mathrm{A} \mathrm{mm}^{-2}\right)$ & $\sim 5900$ & $\sim 5800$ & $\sim 7200$ \\
\hline
\end{tabular}

The MICE magnets AC losses can be estimated by using the average field in each region and dividing the charge and discharge time into time steps.

\section{a) AC Losses in the MICE Coupling Magnets}

The coupling solenoid has the most superconductor of any of the three MICE solenoids, so the AC losses should be the largest. Not only does the coupling solenoid have the more conductor, but it will be cooled with a single cooler rather than two coolers as will be the tracker and focusing solenoids. A magnetic induction map for the coupling coil is shown in Figure 3. The coupling coil was subdivided into five regions. The $r$ and $\mathrm{z}$ dimensions of the regions are shown in Table 2. The approximate worst-case $\Delta \mathrm{B}$ and coil region volume are also shown in Table 2. Region 1 is the center of the coupling coil; region 2 is the outer part of the coupling coil; regions 3 and 4 are the two ends of the coupling coil; and region 5, is the region next to the inner bore of the coupling coil. Equation 2 was applied for each time step with an average $B$, an average $j_{c}$ and a $\Delta B$ for each time step in each coil region during that time step. The total energy released during a charge or discharge was also calculated along with the AC loss per time step. 


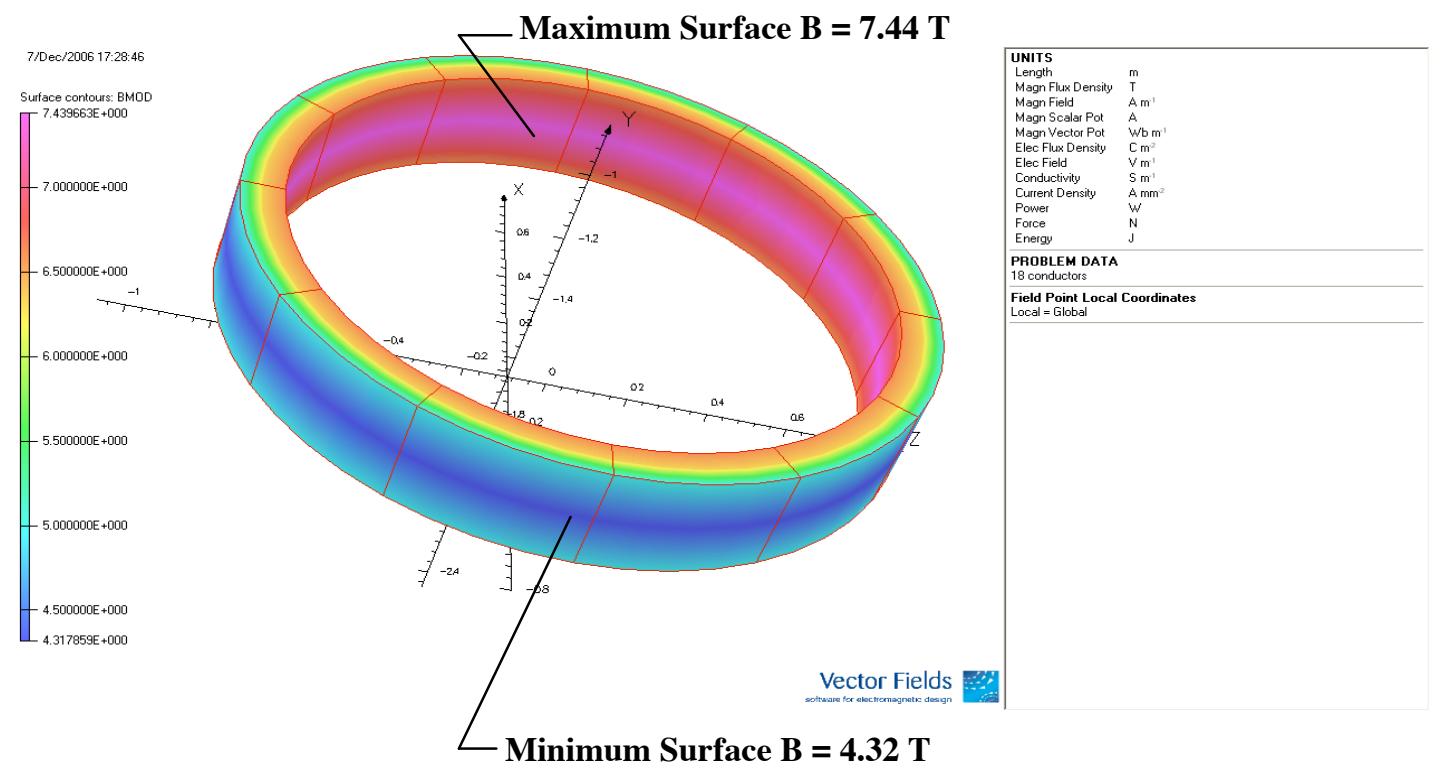

Figure 3. The Magnetic Induction in the Coupling coil with $210.8 \mathrm{~A}$ in the Coil (This corresponds to $\beta=420 \mathrm{~mm}$ and an average momentum of $240 \mathrm{MeV} / \mathrm{c}$ in the flip mode.)

Table 2. The Coupling Coil Sub-division Dimensions, the Coil Region Volume, and the Coil Region Induction Change for $210.8 \mathrm{~A}$ in the Coil

\begin{tabular}{lccccc}
\hline \hline \multicolumn{1}{c}{ Parameter } & Region 1 & Region 2 & Region 3 & Region 4 & Region 5 \\
\hline Minimum R $(\mathrm{mm})^{\wedge}$ & 775 & 827.5 & 775 & 775 & 750 \\
Maximum R $(\mathrm{mm})^{\wedge}$ & 827.5 & 852.5 & 827.5 & 827.5 & 775 \\
Minimum Z $(\mathrm{mm})^{\wedge}$ & -72.5 & -142.5 & -142.5 & +142.5 & -142.5 \\
Maximum Z $(\mathrm{mm})^{\wedge}$ & +72.5 & +142.5 & -72.5 & +72.5 & +142.5 \\
Coil Volume $\left(\mathrm{m}^{3}\right)$ & 0.0413 & 0.0373 & 0.0199 & 0.0199 & 0.0338 \\
Average B in Region $(\mathrm{T})^{*}$ & $\sim 1.6$ & $\sim 4.0$ & $\sim 4.4$ & $\sim 4.4$ & $\sim 6.0$ \\
\hline \hline
\end{tabular}

${ }^{\wedge}$ Note: $\mathrm{R}=0$ is defined as the axis of the solenoid; $\mathrm{Z}=0$ is defined as the center of the coil.

* The worst-case current of $210.8 \mathrm{~A}$ is based on $\mathrm{p}=240 \mathrm{MeV} / \mathrm{c}$ and $\beta=420 \mathrm{~mm}$ in the flip mode.

Table 3 shows the hysteretic loss and mandrel loss for each time step for a $9 \mathrm{~V}$ charge of the coupling magnet (a charge time of 13860 seconds).

Table 3. The Hysteretic and Mandrel Losses for Each Time Step in the Coupling Magnet

\begin{tabular}{cccc}
\hline \hline Time $(\mathbf{s e c})$ & Hysteretic Loss $(\mathbf{W})$ & Mandrel Loss $(\mathbf{W})$ & Total Loss $(\mathbf{W})$ \\
\hline 693 & 1.75 & 0.028 & 1.778 \\
2079 & 1.14 & 0.028 & 1.168 \\
3465 & 0.90 & 0.028 & 0.928 \\
4851 & 0.78 & 0.028 & 0.808 \\
6237 & 0.67 & 0.028 & 0.698 \\
7623 & 0.60 & 0.028 & 0.628 \\
9009 & 0.54 & 0.028 & 0.568 \\
10395 & 0.49 & 0.028 & 0.518 \\
11781 & 0.45 & 0.028 & 0.478 \\
13167 & 0.42 & 0.028 & 0.448 \\
\hline \hline
\end{tabular}


From table 3 one can see that the total thermal energy released by the magnet due to the AC losses in the coil and the magnet mandrel is about $11120 \mathrm{~J}$. The superconductor coupling losses have been neglected because they are very low. The average AC loss for the magnet over the charge is about $0.80 \mathrm{~W}$. The total AC loss does not consider the effects of superconductor penetration nor does it consider the effects of the transport current on the hysteretic losses. Both effects will reduce the AC losses during a charge.

If one uses an average $\Delta \mathrm{B}$ of $3.9 \mathrm{~T}$ and an average $\mathrm{j}_{\mathrm{c}}$ of $5.4 \times 10^{9} \mathrm{~A} \mathrm{~m}^{-2}$ (for an average induction during the charge of $1.95 \mathrm{~T}$ ), and $\mathrm{d}_{\mathrm{f}}=41 \mu \mathrm{m}$ (This filament diameter is the same as the tracker magnet conductor.), one gets a hysteretic AC energy loss during a magnet charge of about $8700 \mathrm{~J}$. The mandrel AC loss is about $390 \mathrm{~J}$. The total AC loss for a 13860 second charge (9 volts across the magnet) is about $9090 \mathrm{~J}$. This represents an average AC loss of $0.66 \mathrm{~W}$ during the entire magnet charge.

It is clear that just using average conditions over the whole coil volume understates the total AC loss. The AC losses at low field are higher than they are at high fields. Flux penetration into the super conductor will reduce the AC losses at the start of the charge. Figure 4 shows a plot of the charging $\mathrm{AC}$ loss as a function of time during a $9 \mathrm{~V}$ charge. Figure 4 shows that superconductor penetration will reduce the AC loss at the beginning of the charge. The effect of the transport current will reduce the AC losses in the high field regions of the coil. This is not considered in Figure 4.

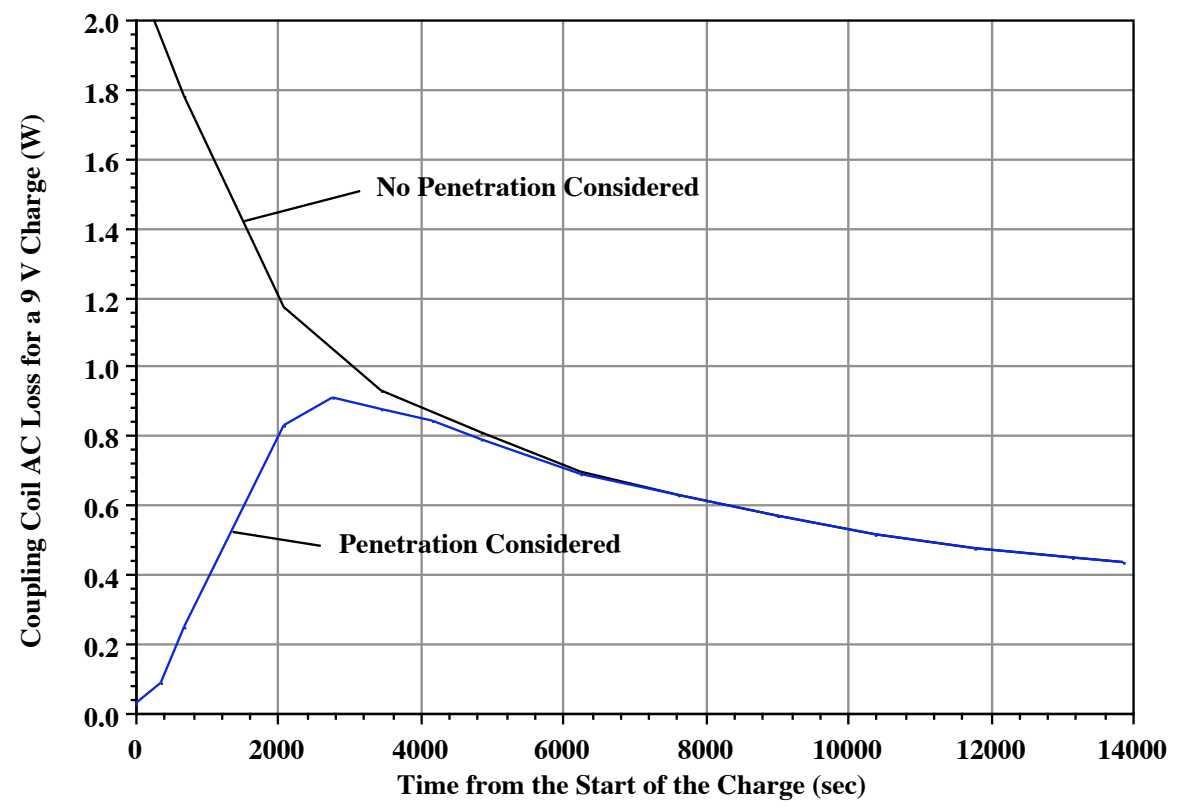

Figure 4. The Total AC Losses for the Coupling Magnet During a 9-Volt Charge as a Function of Time

As one can see from Figure 4, the AC losses can be quite high particularly at the start of the charge. Even with penetration effects considered, the coupling magnet AC losses will approach 1 watt early in a 9-volt charge. This level of AC loss plus the static losses are too high to be removed by a single $1.5 \mathrm{~W}$ pulsed tube cooler. If one discharges the magnet at 9 volts, the AC losses at the end of the discharge will be over 2 watts. One has three choices, one can reduce the charging and discharging voltages in order to run with a single cooler; or one can operate the magnet on two coolers; or one can vent helium during a magnet charge or discharge. The last method will be discussed later. 
It is desirable that one be able to discharge the magnet rapidly, particularly during a power outage or when the tops of the HTS leads get too hot. A rapid-discharge would be induced by switching a resistor across the coils. This amount of resistance across the coil for a fast discharge is determined by the number of diodes in the quench protection system. (Use $\sim 4$ volts per diode.) This voltage is too low to trigger the quench protection diodes and quench the magnet. Table 3 and Figure 5 show the AC losses during a rapid discharge of 5400 seconds, which puts $22.1 \mathrm{~V}$ across the magnet.

Table 3. The Hysteretic and Mandrel Losses for Each Time Step in the Coupling Magnet

\begin{tabular}{cccc}
\hline \hline Time $(\mathbf{s e c})$ & Hysteretic Loss $(\mathbf{W})$ & Mandrel Loss $(\mathbf{W})$ & Total Loss $(\mathbf{W})$ \\
\hline 270 & 1.080 & 0.184 & 1.164 \\
810 & 1.160 & 0.184 & 1.344 \\
1350 & 1.260 & 0.184 & 1.444 \\
1890 & 1.380 & 0.184 & 1.564 \\
2430 & 1.530 & 0.184 & 1.714 \\
2970 & 1.710 & 0.184 & 1.894 \\
3510 & 1.990 & 0.184 & 2.174 \\
4050 & 2.320 & 0.184 & 2.504 \\
4590 & 2.920 & 0.184 & 3.104 \\
5130 & 4.500 & 0.184 & 4.684 \\
\hline \hline
\end{tabular}

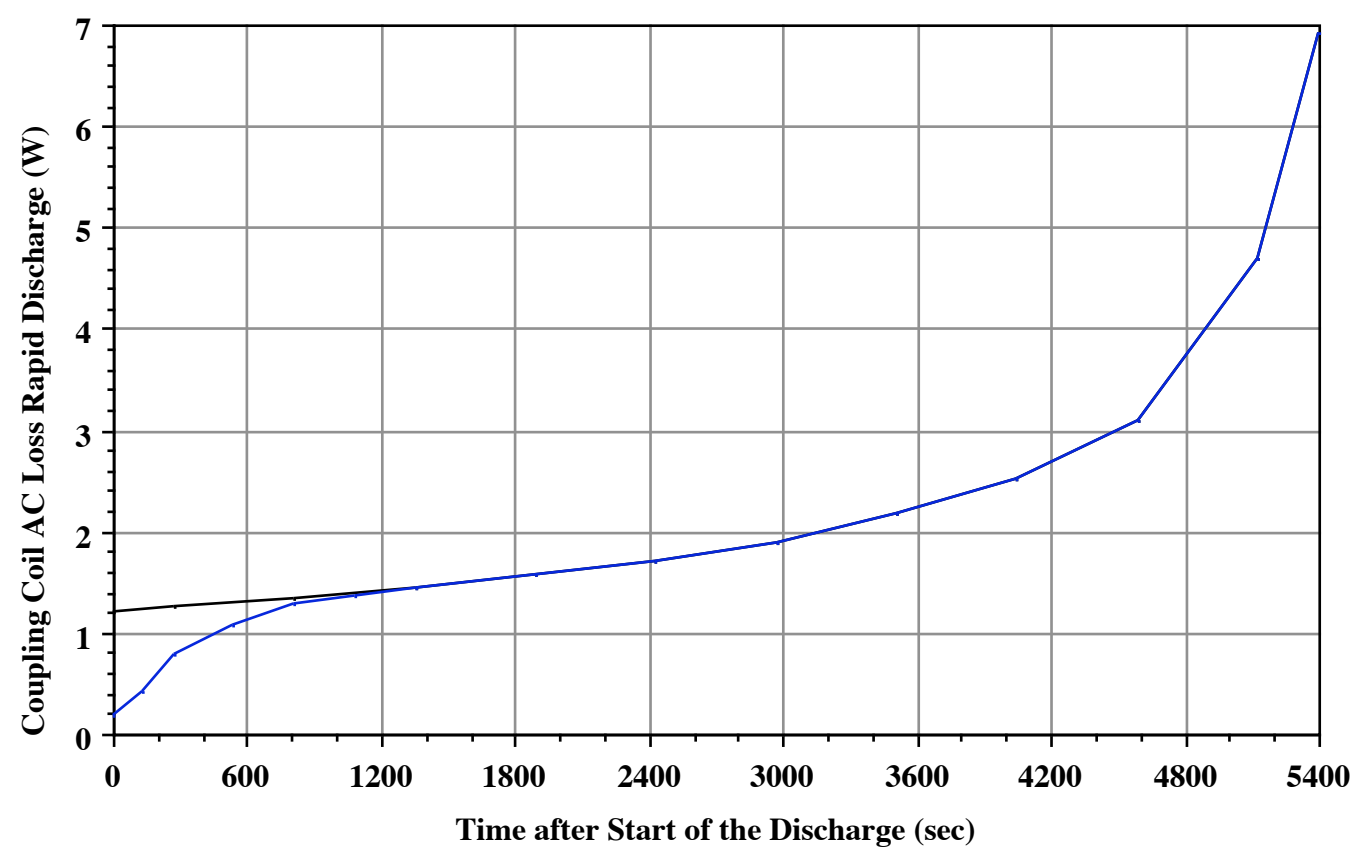

Figure 5. Coupling Magnet Total AC Losses Versus Time during a 5400 second Rapid-discharge (with constant voltage of 22.2 volts put across the coupling magnet)

During a rapid discharge about $13100 \mathrm{~J}$ will be dumped into the coil and the mandrel. The average AC loss over the rapid discharge will be about $3.64 \mathrm{~W}$. This can only be removed by boiling away about 5.3 liters helium from around the magnet. Boiling helium around the magnet is the only option for keeping the magnet cold during a rapid discharge. We shall see later the helium boil off gas can be put to good use. 


\section{b) AC Losses in the Focusing Magnet}

The hysteretic AC losses in the focusing magnet are estimated by scaling the AC losses in the coupling coil. The following scaling factors are applied to estimate the average hysteretic $\mathrm{AC}$ loss for the focusing magnet;

$$
Q_{A C F}=Q_{A C C} \frac{j_{c a F}}{j_{c a C}} \frac{\Delta B_{F}}{\Delta B_{C}} \frac{d_{f F}}{d_{f C}} \frac{V_{F}}{V_{C}} \frac{t_{c h C}}{t_{c h F}}
$$

where $\mathrm{Q}_{\mathrm{ACF}}$ is the average $\mathrm{AC}$ loss for the focusing magnet, and $\mathrm{Q}_{\mathrm{ACC}}$ is the average $\mathrm{AC}$ loss for the coupling magnet. $\mathrm{J}_{\mathrm{caF}}$ is the average $\mathrm{J}_{\mathrm{c}}$ for the focusing magnet conductor, and $\mathrm{J}_{\mathrm{cac}}$ is the average $\mathrm{J}_{\mathrm{c}}$ for the coupling magnet conductor. $\Delta \mathrm{B}_{\mathrm{F}}$ is the average magnetic induction change in the focusing magnet, and $\Delta \mathrm{B}_{\mathrm{C}}$ is the average magnetic induction change in the coupling magnet. The symbol $\mathrm{d}_{\mathrm{fF}}$ is the diameter of the focusing magnet conductor filaments; $d_{\mathrm{fC}}$ is the diameter of the coupling magnet filaments. $V_{\mathrm{F}}$ is the volume of the focusing magnet coils, and $\mathrm{V}_{\mathrm{C}}$ is the volume of the Coupling magnet coils. The value $t_{\text {chF }}$ is the charge time for the focusing magnet, and $t_{\text {chC }}$ is the charge time for the coupling magnet.

It is assumed that the focusing magnet conductor filament diameter is the same as that assumed for the tracker magnet conductor $\left(\mathrm{d}_{\mathrm{fC}}=41 \mu \mathrm{m}\right)$. Using the values given in Table 1 one finds that the average hysteretic AC loss of the focusing coil during charging at the full voltage the power supply allows is $0.63 \mathrm{~W}$. The mandrel AC loss is about $0.024 \mathrm{~W}$. The peak AC loss during a magnet charge is about $0.75 \mathrm{~W}$ (see Figure 6). The AC loss energy dumped into the magnet during a rapid discharge is about $5500 \mathrm{~J}$. The $\mathrm{AC}$ loss due to the mandrel is about $0.107 \mathrm{~W}$. The peak AC loss during a rapid discharge (see Figure 7) is about $4.7 \mathrm{~W}$ at the end of the discharge.

It is likely that a pair of $1.5 \mathrm{~W}$ pulse tube coolers can handle the charging heat $\mathrm{AC}$ loss plus the static losses, but it is clear that the focusing coil coolers can't handle the AC loss plus static heat load during a rapid discharge. As with the coupling coil, one must expect to boil off some helium. About 2.2 liters of helium will be boiled away.

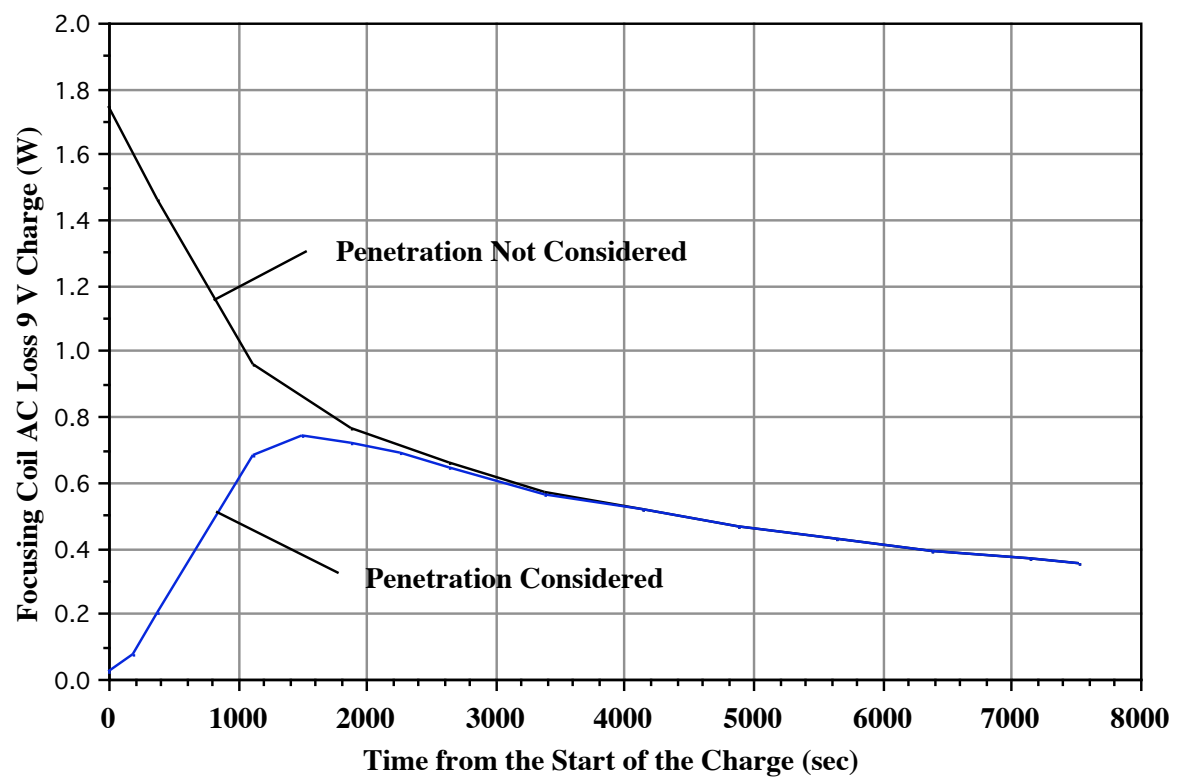

Figure 6. The Total AC Losses for the Focusing Magnet During a 9-Volt Charge as a Function of Time 


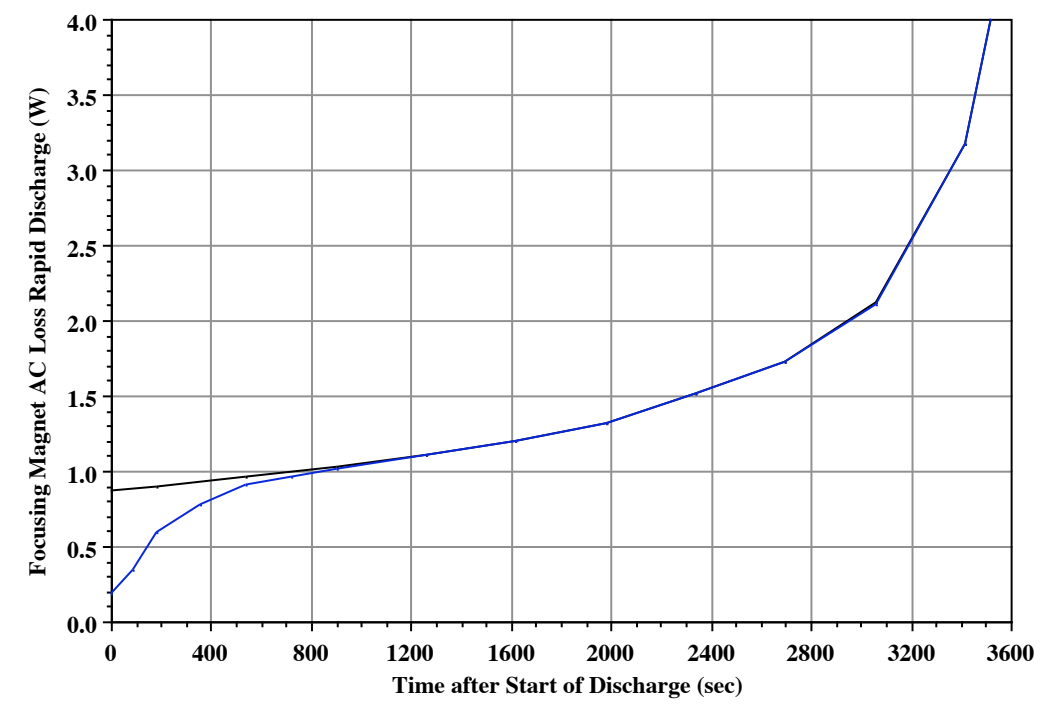

Figure 7. Focusing Magnet Total AC Losses Versus Time during a 3600 second Rapid Discharge

\section{c) AC Losses in the Tracker Magnet}

The hysteretic $\mathrm{AC}$ losses in the focusing magnet are estimated by scaling the $\mathrm{AC}$ losses in the coupling coil. The following scaling factors are applied to estimate the average hysteretic $\mathrm{AC}$ loss for the focusing magnet;

$$
Q_{A C T}=Q_{A C C} \frac{j_{c a T}}{j_{c a C}} \frac{\Delta B_{T}}{\Delta B_{C}} \frac{d_{f T}}{d_{f C}} \frac{V_{T}}{V_{C}} \frac{t_{c h C}}{t_{c h T}}
$$

where $\mathrm{Q}_{\mathrm{ACT}}$ is the average $\mathrm{AC}$ loss for the tracker magnet, and $\mathrm{Q}_{\mathrm{ACC}}$ is the average $\mathrm{AC}$ loss for the coupling magnet. $\mathrm{J}_{\mathrm{caT}}$ is the average $\mathrm{J}_{\mathrm{c}}$ for the tracker magnet conductor, and $\mathrm{J}_{\mathrm{cac}}$ is the average $\mathrm{J}_{\mathrm{c}}$ for the coupling magnet conductor. $\Delta \mathrm{B}_{\mathrm{T}}$ is the average magnetic induction change in the focusing magnet, and $\Delta \mathrm{B}_{\mathrm{C}}$ is the average magnetic induction change in the coupling magnet. The symbol $\mathrm{d}_{\mathrm{fT}}$ is the diameter of the tracker magnet conductor filaments; $d_{\mathrm{fC}}$ is the diameter of the coupling magnet filaments. $V_{T}$ is the volume of the focusing magnet coils, and $\mathrm{V}_{\mathrm{C}}$ is the volume of the Coupling magnet coils. The value $t_{\mathrm{chT}}$ is the charge time for the focusing magnet, and $t_{\mathrm{chC}}$ is the charge time for the coupling magnet.

The tracker magnet conductor filament diameter $\mathrm{d}_{\mathrm{fT}}=41 \mu \mathrm{m}$, which is the same as the filament diameter used for the coupling coil AC loss calculations. Using the values given in Table 1 one finds that the average hysteretic AC loss of the focusing coil during charging at the full voltage the power supply allows is $1.01 \mathrm{~W}$. It is assumed that all of the coils in the tracker are charged in 4620 seconds. The average tracker magnet mandrel $\mathrm{AC}$ loss is about $0.036 \mathrm{~W}$. Because the average induction in the tracker magnet is lower, the effect of penetration will be a little different than for the other two magnets. At worst, the peak AC loss during a magnet charge will be about $1.3 \mathrm{~W}$. The average AC loss during a rapid discharge of 1800 seconds is about $3 \mathrm{~W}$. The peak AC loss at the end of a constant voltage discharge could be as high as $5.3 \mathrm{~W}$. The AC loss energy during a rapid discharge is expected to about $5300 \mathrm{~J}$. It is likely that a pair of $1.5 \mathrm{~W}$ pulse tube coolers can handle the charging heat $\mathrm{AC}$ loss plus the static losses, but it is clear that the tracker magnet coolers can't handle the heat load during a rapid discharge. As with the coupling coil, one must expect to boil off a bit over 2 liters of helium at $4.2 \mathrm{~K}$. 


\section{The Rapid Discharge Resistor and its Effect on AC Loss}

The rapid discharge AC losses shown in Figure 5 and Figure 7 are based on putting a constant voltage across the leads of the magnet. In the case of Figure 5, this constant voltage is $22.2 \mathrm{~V}$. In the case of Figure 7, the constant voltage is $20.6 \mathrm{~V}$. The voltage across the magnet is in reality more complicated than a simple constant voltage. A much more likely scenario is to dump the magnet stored energy through a combination of the stack of diodes that operate in the forward direction plus a constant resistance. A circuit for producing a rapid discharge in the coupling magnet is shown in Figure 8.

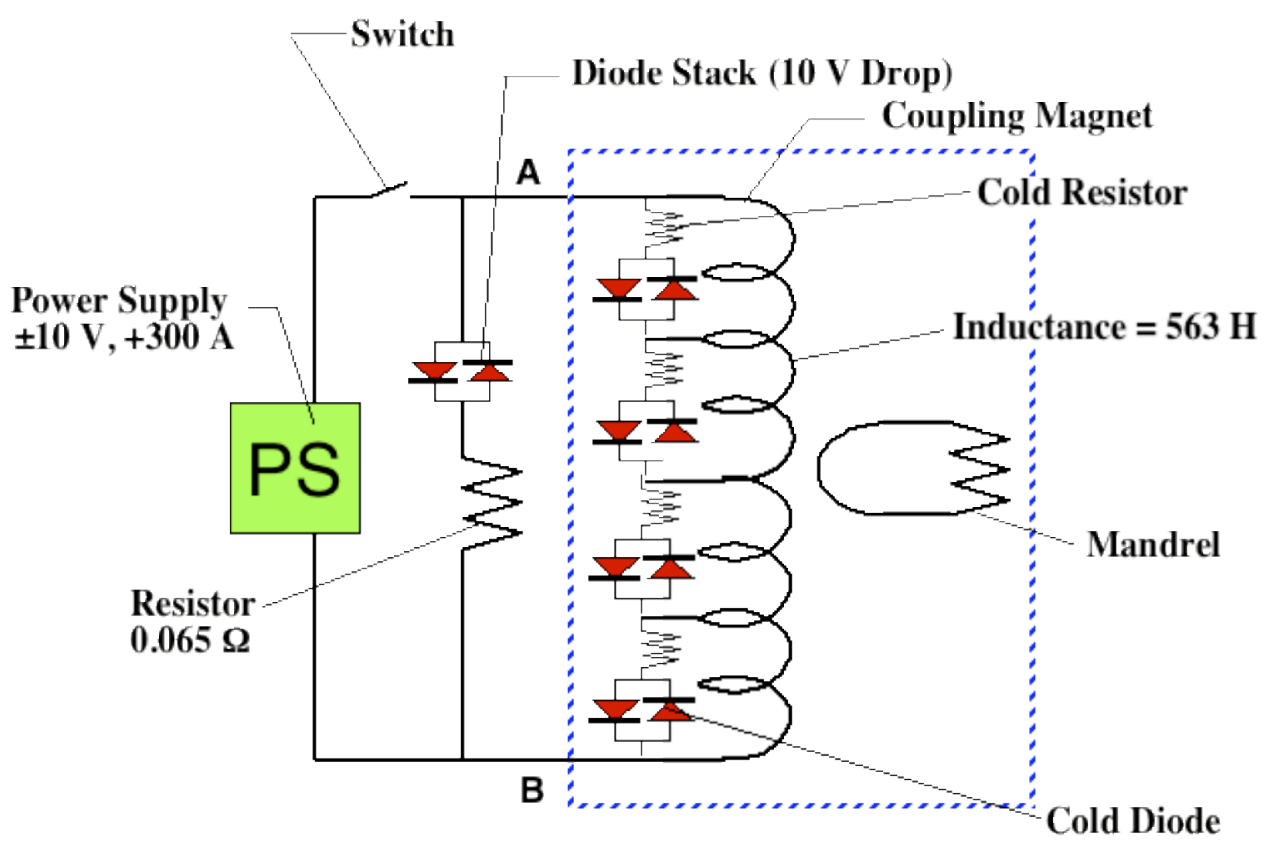

Figure 8. The Coupling Magnet Circuit showing the Rapid Discharge Diodes and Resistor

This circuit puts $23.7 \mathrm{~V}$ across the coupling magnet when it carries discharges at a peak current of $211 \mathrm{~A}$.

The diode stack shown in Figure 8 must pass virtually no current when the magnet is charged and discharged using the power supply. This means that the diode stack should hold off about $10 \mathrm{~V}$ before it starts to carry current in the forward direction. In order to be able to charge and discharge the magnet, the diodes must go both ways as shown in Figure 8. The diodes shown in Figure 8 must be rated to carry 500 A continuously. Ten Power diodes that have a forward voltage of $1 \mathrm{~V}$ can be used for each leg of the stack. These diodes don't carry current except during a rapid discharge, when the switch between the power supply and the resistor is opened.

At a peak current of 211 A about $2.1 \mathrm{~kW}$ is generated in stack of ten diodes, so adequate cooling must be provided. The resistor in series with the diode stack will drop of $13.7 \mathrm{~V}$ when the magnet is charged at its peak current of $211 \mathrm{~A}$. At this current, about $2.9 \mathrm{~kW}$ will be dissipated in the resistor. At $211 \mathrm{~A}$, the effective resistance of the circuit is 0.112 ohms. As the current goes down, the voltage drop across the resistor part of the circuit will go down as the current goes down. The voltage drop across the diode part of the circuit will remain nearly constant. At a magnet current of $100 \mathrm{~A}$, about $1.65 \mathrm{~kW}$ will be dissipated in the resistor and diode pack. At $100 \mathrm{~A}$, the effective circuit resistance is about 0.165 ohms: at $50 \mathrm{~A}$, the circuit effective resistance increases to $0.265 \mathrm{ohms}$. 
Figure 9 shows the coupling magnet current as it goes through a rapid discharge. The linear curve shows a 5400 second rapid discharge where a constant voltage is put across the magnet. The second curve in Figure 9 shows the current versus time for the circuit shown in Figure 8, when the diode pack drops ten volts. The second curve reflects the fact that the voltage across the magnet is not constant. Figure 10 shows the expected AC loss in the coupling coil for the second curve in Figure 9.

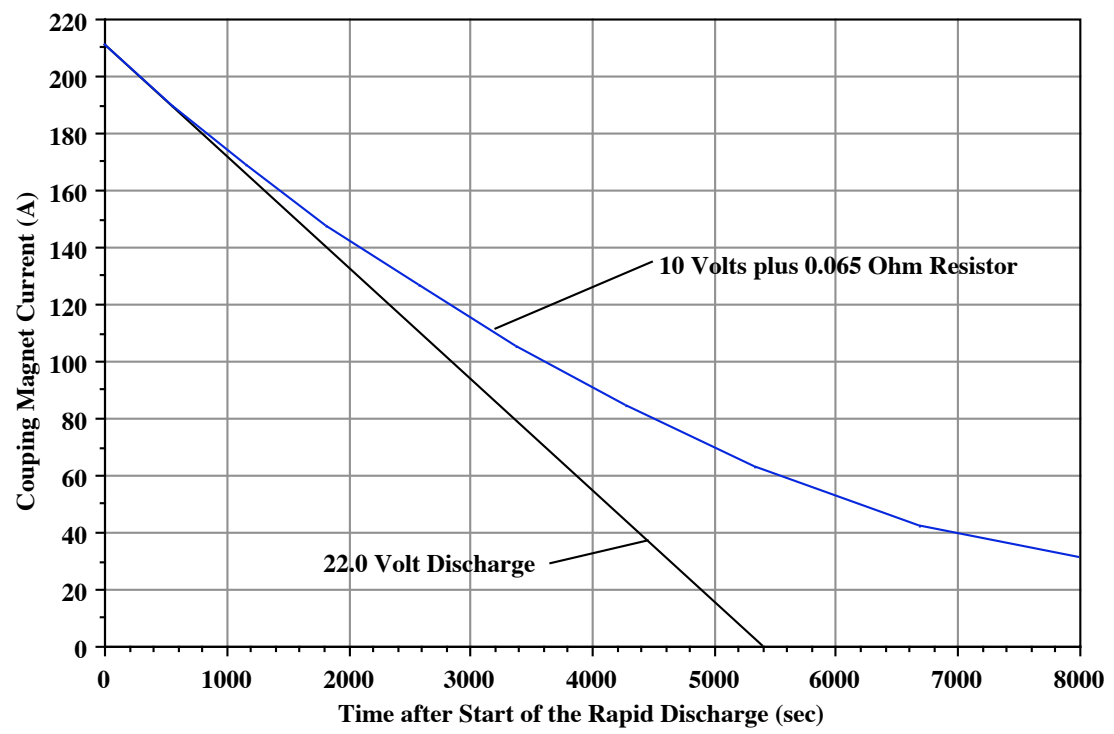

Figure 9. Current versus Time for a Coupling Coil Discharge at a constant 22.2 V and for the Circuit shown in Figure 8

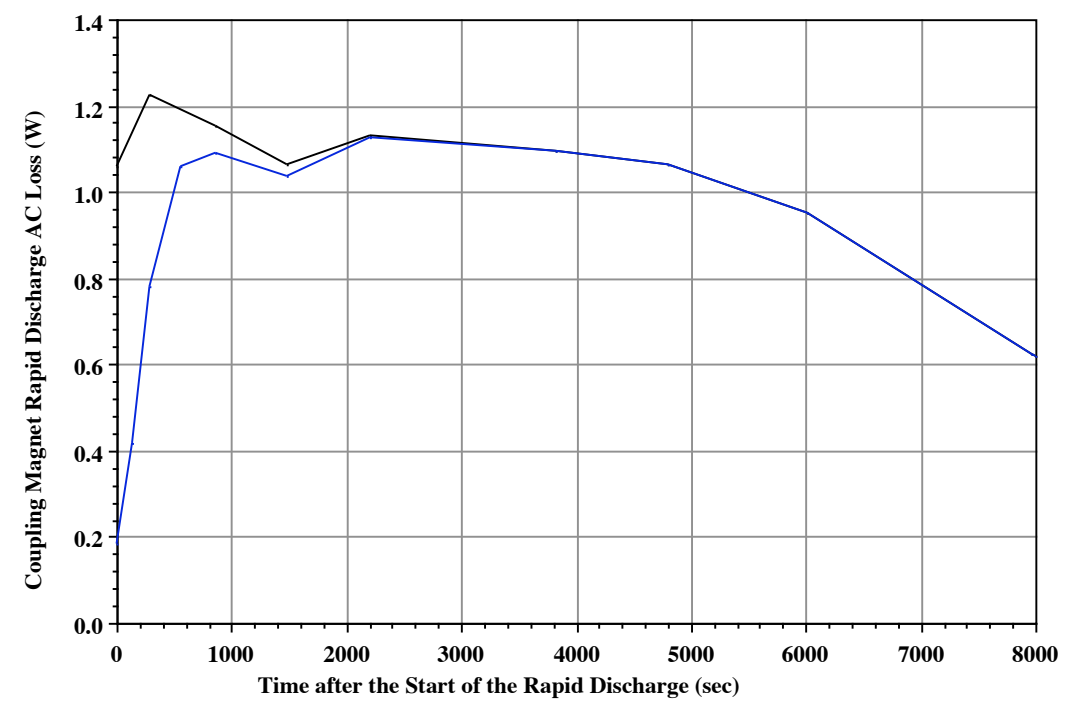

Figure 10. The AC Loss in the Coupling Magnet for a Discharge using the Circuit shown in Figure 8

The effect of the circuit in Figure 8 is to lengthen the discharge (see Figure 9), and as a result, the $\mathrm{AC}$ losses are reduced for a given time. Figure 10 should be compared with the coupling coil rapid discharge AC loss shown in Figure 5. The total helium boil off is slightly lower over the time needed to discharge the magnet. 


\section{Heat Leak down Conduction Cooled Leads}

Powered magnets that are cooled using small coolers have HTS-leads between the cooler first-stage and the cooler second-stage. Between room temperature and the cooler first-stage the leads are conduction-cooled to the cooler first-stage. In general, the conduction-cooled leads are optimized to a current that is near the maximum magnet current. The MICE coupling and focusing magnet leads are optimized to 80 percent of the current needed for $\mathrm{p}=240 \mathrm{MeV} / \mathrm{c}$ and $\beta=420 \mathrm{~mm}$ in the center of the absorber. The tracker magnet optimum-current is $270 \mathrm{~A}$ for the spectrometer magnet and the two match coils. The small leads used for tuning are optimized for a current of $60 \mathrm{~A}$.

A conduction-cooled lead or a gas cooled lead is optimized so that the net heat flow in the top of the lead (at say $293 \mathrm{~K}$ ) is zero. When a conduction-cooled lead is operating at its optimum-current, all of the heat leaving the lead at the bottom is from resistive heating. (The same statement is true for a gas-cooled power lead as well.) An optimumlead has $\mathrm{dT} / \mathrm{dx}=0$ at the room temperature end of the lead, when it is operating at its optimum current $I_{0}$. The heat leak down a lead to the cooler first-stage (without gas cooling) can be calculated using the following expression [10], [11];

$$
Q_{I}=\left[L_{o}\left(T_{R}^{2}-T_{1}^{2}\right)\right]^{0.5} I_{o} \approx 3.6 \frac{k_{B} T_{R}}{e} I_{o}
$$

where $Q_{I}$ is the heat leak down an optimum lead carrying a current $I_{0}$ with an upper end temperature $T_{R}\left(T_{R}\right.$ is room temperature.) and a lower end temperature $T_{1}\left(T_{1}\right.$ is the cooler first-stage temperature. $\mathrm{L}_{\mathrm{o}}$ is the Lorenz number; $\mathrm{k}_{\mathrm{B}}$ is Bolzmann's constant; and e is the charge of an electron. (Nominally $\mathrm{L}_{\mathrm{o}}=2.45 \times 10^{-8} \mathrm{~W} \Omega \mathrm{K}^{-2} ; \mathrm{k}_{\mathrm{B}} 1.38 \times 10^{-23} \mathrm{~J} \mathrm{~K}^{-1}$ and the charge of an electron $\mathrm{e}=1.6 \times 10^{-19}$ coulomb.) When the lead operates at its optimum current with $\mathrm{T}_{\mathrm{R}}=293 \mathrm{~K}$ and $\mathrm{T}_{1}=60 \mathrm{~K}, \mathrm{Q} / \mathrm{I}_{\mathrm{o}}=0.045 \mathrm{~W} \mathrm{~A}^{-1}$ per lead.

The other lead design issue is the $\mathrm{I}_{\mathrm{o}} \mathrm{L} / \mathrm{A}$ function that relates the lead design current $I_{o}$ to the lead length $L$ and cross-section area $A_{c}$. One can estimate the IL/A for a current lead with a design current $\mathrm{I}_{\mathrm{o}}$ (whether it is gas-cooled or not) by using the following approximate expression [12];

$$
\frac{I_{o} L_{L}}{A_{c}}=j_{o} L_{L}=\frac{Q_{1}}{I_{o} \rho_{e f f}} \approx 286\left[\rho\left(T_{1}\right)\right]^{0.5}
$$

where $L_{L}$ is the lead length; $A_{c}$ is the lead cross-section area; $j_{o}$ is the lead current density; $\rho\left(T_{1}\right)$ is the lead conductor resistivity at the bottom of the lead (at temperature $T_{1}$ ) and $\rho_{\text {eff }}$ is the effective resistivity of the lead. The IL/A given by equation 24 is approximate, but it is reasonable to use this equation. It is clear that leads made from high RRR material (a pure metal) have a lower $\rho_{\text {eff }}$, and as a result, leads will be longer. Leads that are made from pure metals (such as RRR $=300$ copper) do not operate well when the current is even 20 percent over the design current. Low RRR leads are much shorter, and they can operate off their optimum current without much penalty [10].

The calculation of the cross-section comes from the adiabatic burnout equation for a metal lead. The expression that this is derived from is the same expression as is used for the quench hot-spot temperature in a superconducting magnet [12]. The equation for lead burn-out can be stated as follows [12], [13]; 


$$
F *(T)=\int_{T_{S}}^{T_{F}} \frac{C(T)}{\rho(T)} d T=\int_{0}^{t} j(t)^{2} d t
$$

where $C(T)$ is the specific heat per unit volume as a function of temperature $T ; \rho(T)$ is the electrical resistivity as a function of $\mathrm{T}$; and $\mathrm{j}(\mathrm{t})$ is the current density in the conductor cross-section as a function of time $\mathrm{t}$. Note; $\mathrm{j}(\mathrm{t})=\mathrm{I}(\mathrm{t}) / \mathrm{A}_{\mathrm{c}}$. Equation 25 can be simplified to apply over a range of temperatures from $\mathrm{T}_{\mathrm{S}}$ ( say $300 \mathrm{~K}$ ) and $\mathrm{T}_{\mathrm{F}}($ say $400 \mathrm{~K}$ ). When the current in the magnet supplied by the leads decays with an L/R time constant $\tau_{M}$ across a simple resistor the equation for the lead cross-section area (based on the adiabatic condition where not heat flows out of the lead) takes the following form [14];

$$
A_{c}=I_{o}\left[\frac{\tau_{M} \rho_{a v e}}{2 C_{a v e}\left(T_{F}-T_{S}\right)}\right]^{0.5}
$$

When the simple resistor is replaced by a perfect varistor, the cross-section area for the lead using the following expression;

$$
A_{c}=I_{o}\left[\frac{\tau_{M} \rho_{a v e}}{3 C_{a v e}\left(T_{F}-T_{S}\right)}\right]^{0.5}
$$

In both equations $26 \mathrm{a}$ and $26 \mathrm{~b}, \rho_{\mathrm{ave}}$ is the average resistivity at $\mathrm{T}=\left(\mathrm{T}_{\mathrm{S}}+\mathrm{T}_{\mathrm{F}}\right) / 2$ and $\mathrm{C}_{\mathrm{ave}}$ is the specific heat per unit volume at $\mathrm{T}=\left(\mathrm{T}_{\mathrm{S}}+\mathrm{T}_{\mathrm{F}}\right) / 2$. For a $\mathrm{RRR}=5$ copper with $\mathrm{T}_{\mathrm{S}}=300$ $\mathrm{K}$ and $\mathrm{T}_{\mathrm{F}}=400 \mathrm{~K}, \rho_{\mathrm{ave}}=2.3 \times 10^{-8} \Omega \mathrm{m}$ and $\mathrm{C}_{\mathrm{ave}}=4.14 \times 10^{6} \mathrm{~W} \mathrm{~m}^{-2} \mathrm{~K}^{-1}$.

It can be argued that the adiabatic equations given above don't really apply, because heat is flowing from both lead ends. Leads running at a high current density are shorter than leads running at a lower current density. Experience with gas-cooled leads suggests that the design lead current density $j_{\mathrm{o}}$ should be set at around $1 \times 10^{7} \mathrm{~A} \mathrm{~m}^{-2}$ [13], [14]. This current density is about an order of magnitude larger than the current density given by the equations above.

An optimum lead has no net heat flow at the room temperature end [10,11]. All of the heat that leaves the lead at its low temperature end comes from $i^{2} R$ heating. At currents greater than the lead optimum design current, there is heat flowing out of the lead from the room temperature end. At currents less than the lead optimum design current, there is heat flowing into the lead from the room temperature end. Because the heat is from two separate sources, the heat flow from the low temperature end of the lead at zero current is half of the heat flow from the low temperature end of the lead, when the lead operates at its optimum current. Wilson's study of gas-cooled stated that the cold end heat leak at zero current is from 40 to 70 percent of the cold end heat leak at the optimum current, depending on the RRR of the copper. If IL/A is correct, heat leak at zero current for conduction-cooled leads will be half the heat flow when the lead is operating at its design current (regardless of the metal used to fabricate the lead) [11].

The heat flow from the room temperature end $\left(T_{R}=\sim 300 \mathrm{~K}\right)$ to the low temperature end $\left(\mathrm{T}_{1}=\sim 60 \mathrm{~K}\right)$ of a constant cross-section conduction cooled leads can be calculated using the following approximate expression; 


$$
Q_{0}=\frac{A_{c}}{L_{L}} \int_{T_{1}}^{T_{R}} k(T) d T
$$

where $\mathrm{Q}_{0}$ is the heat flow at the cold end of the single lead; $\mathrm{A}_{\mathrm{c}}$ is the cross-section area of the lead (Note, $A_{c}=\sim 10^{-7} \mathrm{I}_{\mathrm{o}}$.) ; $\mathrm{L}_{\mathrm{L}}$ is the length of the lead; and $\mathrm{k}(\mathrm{T})$ the lead material thermal conductivity as a function of temperature $\mathrm{T}$. Table 4 shows the design parameters for two types conduction cooled leads. One lead is fabricated from $R R R=5$ copper; the other lead is fabricated from RRR $=30$ copper. Similar calculations could be made for leads fabricated from other materials.

Table 4. The Design Parameters for Conduction Cooled Leads Fabricated from RRR $=5$ and RRR $=30$ Copper

\begin{tabular}{|c|c|c|}
\hline Lead Parameters & $\mathbf{R R R}=5 \mathbf{C u}$ & $\mathbf{R R R}=30 \mathrm{Cu}$ \\
\hline Top End Temperature (K) & \multicolumn{2}{|c|}{293} \\
\hline Bottom End Temperature (K) & \multicolumn{2}{|c|}{60} \\
\hline Powered Lead Heat Leak $\left(\mathrm{W} \mathrm{A}^{-1}\right)$ & \multicolumn{2}{|c|}{0.045} \\
\hline Bottom End Resistivity $(\Omega \mathrm{m})$ & $4.06 \times 10^{-9}$ & $2.77 \times 10^{-9}$ \\
\hline Lead $\mathrm{I}_{0} \mathrm{~L}_{\mathrm{L}} / \mathrm{A}_{\mathrm{c}}$ from Eq. $[24]\left(\mathrm{A} \mathrm{m}^{-1}\right)$ & $4.49 \times 10^{6}$ & $5.43 . \times 10^{6}$ \\
\hline Lead Current Density $\left(\mathrm{A} \mathrm{m}^{-2}\right)$ & $10^{7}$ & $10^{7}$ \\
\hline Optimum Lead Length (m) & 0.449 & 0.543 \\
\hline $\int \mathrm{k}(\mathrm{T}) \mathrm{dT}$ from 60 to $293 \mathrm{~K}\left(\mathrm{~W} \mathrm{~m}{ }^{-1}\right)$ & $8.7 \times 10^{4}$ & $10.7 \times 10^{4}$ \\
\hline Un-powered Lead Heat Leak $\left(\mathrm{W} \mathrm{A}^{-1}\right)$ & 0.0193 & 0.0196 \\
\hline Ratio (Un-powered Q)/(Powered Q) & 0.431 & 0.440 \\
\hline
\end{tabular}

The ratio of un-powered heat leak to the powered heat leak at optimum current in Table 4 is around 44 percent. This suggests that the calculated IL/A using equation 24 may be too large by about 12 percent. The ratio shown in the table is nearly the same ratio that Wilson [10] calculates for low RRR gas-cooled copper leads.

For the coupling coil, the calculated powered heat leak is $15.1 \mathrm{~W}$ per lead pair when the magnet current is $168 \mathrm{~A}$. When the coupling coil current is increased to $210 \mathrm{~A}$, the heat leak down the leads is about $19.6 \mathrm{~W}$. For an un-powered leads the estimated heat leak down the leads is about 7.6 W. During a rapid discharge of the magnet from $210 \mathrm{~A}$ to zero, the average heat leak could be as low as $13.6 \mathrm{~W}$. An average lead heat leak down the leads of $16 \mathrm{~W}$ will be used for a rapid discharge in Table 5 in the next section.

For the focusing coil, the calculated powered heat leak is $36 \mathrm{~W}$ for four leads when the magnet current is $200 \mathrm{~A}$. When the focusing magnet current is increased to $250 \mathrm{~A}$, the heat leak down the leads is about $47 \mathrm{~W}$. For an un-powered leads the estimated heat leak down the leads is about $16 \mathrm{~W}$. During a rapid discharge of the magnet from $250 \mathrm{~A}$ to zero, the average heat leak could be as low as $32 \mathrm{~W}$. An average lead heat leak down the leads of $36 \mathrm{~W}$ will be used for a rapid discharge in Table 5 in the next section.

The six primary leads for the tracker solenoid carry about $270 \mathrm{~A}$. At this current, the heat leaks down these leads will be about $73 \mathrm{~W}$. At zero current the six primary leads will have a heat leak of about $37 \mathrm{~W}$. The tuning leads are designed to carry about $60 \mathrm{~A}$. A pair of these leads will have a powered heat leak of about $5.4 \mathrm{~W}$. At zero current these leads will have a heat leak of about $2.7 \mathrm{~W}$. The tracker magnet average lead heat leak during a rapid discharge could be as low as $58 \mathrm{~W}$. An average lead heat leak down the leads of $60 \mathrm{~W}$ will be used for a rapid discharge in Table 5 in the next section. 


\section{Cooling the Top of the HTS Leads Using the Helium Boil Off Gas}

It is clear that AC losses will be a factor in determining how the MICE magnets will be charged and discharged. All of the MICE magnets can be charged at the full voltage available from the power supply. The coupling magnet $\mathrm{AC}$ losses are too high to be cooled using a single $1.5 \mathrm{~W}$ pulse tube cooler. It appears that the focusing and tracker magnets can be cooled with two coolers while being charged at the full voltage available from the power supply. None of the MICE magnets can be discharged rapidly without boiling off some of the liquid helium that is around the magnet coils. A rapid discharge of the coupling magnet (in 5400 seconds) will boil off 5.3 liters of helium (about $0.66 \mathrm{~kg}$ ) at $4.22 \mathrm{~K}$. A rapid discharge of the focusing magnet (in 3600 seconds) will boil off about 2.2 liters of helium (about $0.28 \mathrm{~kg}$ ) at $4.22 \mathrm{~K}$. A rapid discharge of the tracker magnet (in 1800 seconds) will boil off over 2 liters of helium about $0.25 \mathrm{~kg}$ ) at $4.22 \mathrm{~K}$.

At temperatures and pressures above the 1 atmosphere boiling point for helium, the boil off rate will be higher. For example, if the relief pressure is set to 1.4 bar, the boiling temperature will go up to $4.58 \mathrm{~K}$. At $4.58 \mathrm{~K}$, the mass of helium boiled is increased by about 14.6 percent, because the heat of vaporization is lower at this temperature. Since helium has a lower density at $4.58 \mathrm{~K}$ that it does at $4.22 \mathrm{~K}$ the volume of helium boiled off increases 22.5 percent. For extra margin, the available helium volume for a rapid discharge should be increased by fifty percent. The fact that helium will be boiled away during charging (the coupling magnet) and rapid discharging (all magnets) is the curse of having AC losses in the conductor. It should be noted that the total AC loss is dominated by the hysteretic AC loss. To first order, this means that the helium boiled away during a charge or discharge of a MICE magnet will be approximately proportion to the diameter of the filaments in the superconductor.

The helium that is boiled during a charge or discharge can be collected and be reliquefied, if the helium loss is a concern. The critical question is what should be done with the sensible heat that is in the helium that is boiled away. Much of the sensible heat from the helium (up to 70 percent) can be used to cool the top of the HTS leads and even the copper leads. At the very minimum, the sensible heat from the helium should be used to cool the shield region right around the HTS leads. The sensible heat can be used to capture the heat coming down the copper leads, thus keeping the top of the HTS leads cold. This means that some of the extra shield mass postulated in MICE note 162 [8] is not needed for protecting the leads during a rapid discharge when the power has failed.

The sensible change of enthalpy between the boiling temperature $T_{B}$ and the temperature of the cooler first stage $\mathrm{T}_{1}$ is given by the following expression;

$$
\Delta H_{\text {sen }}=\int_{T_{B}}^{T} C_{p}(T) d T
$$

where $\mathrm{C}_{\mathrm{p}}$ is the specific heat at constant pressure per unit mass and $\mathrm{T}$ is temperature. For helium, the value of $\mathrm{C}_{\mathrm{p}}$ is constant at $5.2 \mathrm{~J} \mathrm{~g}^{-1} \mathrm{~K}^{-1}$ from $5 \mathrm{~K}$ to $300 \mathrm{~K}$ at a pressure of 1 bar. Thus the total sensible enthalpy between $4.22 \mathrm{~K}$ and $60 \mathrm{~K}$ is about $290 \mathrm{~J} \mathrm{~g}^{-1}$.

When one boils about 8.5 liters (with the coolers off) of helium away at $4.22 \mathrm{~K}$ in the coupling solenoid in 5400 seconds, the helium mass flow is $0.197 \mathrm{~g} \mathrm{~s}^{-1}$. When the helium is heated to $60 \mathrm{~K}$ the cooling rate is $56.9 \mathrm{~W}$ of cooling can be supplied to the HTS leads. At $210 \mathrm{~A}$, only $19.7 \mathrm{~W}$ comes down the leads. When the current goes to zero, the average heat load down the leads is $<10 \mathrm{~W}$. There should be net cooling at the top of the HTS leads. There is no need for extra mass in the near the HTS leads (see Table 5). 
When one boils about 5.0 liters of helium away (including the static heat leak) at $4.22 \mathrm{~K}$ in the focusing solenoid in 3600 seconds, the helium mass flow is $0.174 \mathrm{~g} \mathrm{~s}^{-1}$. When the helium is heated to $60 \mathrm{~K}$ the cooling rate is $50.8 \mathrm{~W}$ of cooling can be supplied to the leads. At full current $47 \mathrm{~W}$ of heat comes down the leads ( $36 \mathrm{~W}$ with decreasing current), there is not net heating in the coupling coil leads, so no extra mass is needed around the top of the HTS leads (see Table 5).

When one boils about 3.9 liters of helium away at $4.22 \mathrm{~K}$ (including the static heat leak) in the tracker solenoid in 1800 seconds, the helium mass flow is $0.271 \mathrm{~g} \mathrm{~s}^{-1}$. When the helium is heated to $60 \mathrm{~K}$ the cooling rate is $78.6 \mathrm{~W}$ of cooling can be supplied to the HTS leads. Since $\sim 80 \mathrm{~W}$ of heat comes down the copper leads $(\sim 59 \mathrm{~W}$ with decreasing current), there is just enough cooling to intercept all of the heat that may come down the leads (see Table 5).

One can eliminate all of the extra mass in the shield in all of the MICE magnets if one is willing to cool the copper leads directly using the boil-off gas as the magnet rapidly discharges. Cooling the leads themselves means that four in-line insulators must installed in the helium lines for each pair of leads. This complicates the magnet cryostat and increases the risk of a helium leak into the cryostat vacuum. Cooling the shield around the top of the HTS leads does not require in line insulators.

Table 5. An Estimate Amount of Copper needed to keep the Upper End of the HTS Leads Cold during a Fast Discharge, when AC Loss and Static Heat load Helium Boil Off are considered and not considered

\begin{tabular}{lccccc}
\hline \multicolumn{1}{c}{ Parameter } & AFC & Coupling & M1 & M2 & Tracker \\
\hline Magnet Self Inductance (H) & 98.6 & 563 & 13.0 & 5.4 & $\sim 77.0$ \\
Number of Magnet Turns & 19304 & 15704 & 5040 & 3332 & 23606 \\
Magnet Charge Time (s) & 7540 & 13860 & 4620 & 4620 & 4620 \\
Magnet Charging Voltage (V) & 3.0 & 9.0 & 4.5 & 4.5 & 4.5 \\
Coupling Coefficient to Mandrel & 0.8 & 0.9 & 0.8 & 0.82 & 0.85 \\
Charging AC Loss Heat Load (W) & 0.65 & 0.66 & & 1.01 & \\
Rapid Discharge AC Loss Heat Load (W) & 2.25 & 3.64 & & 4.42 & \\
Design Static Heat Load at 4.2 K (W) & 2.7 & 1.5 & & 2.7 & \\
Time for a Rapid Discharge (s) & 3600 & 5400 & & 1800 & \\
Magnet Fast Discharge Voltage (V) & 6.28 & 22.2 & 3.4 & 3.4 & 11.6 \\
Number of Quench Diode Packs & 2 & 8 & 1 & 1 & 4 \\
Discharge Voltage per Diode Pack (V) & 3.14 & 2.78 & 3.4 & 3.4 & 2.9 \\
Average Copper Lead Heat Flow (W) & 36 & 16 & 18.7 & 18.7 & 22.6 \\
Maximum He Lead Cooling (W) & 50.8 & 56.9 & & 78.6 & \\
Net Heat Flow to the HTS Leads (W) & -14.8 & -40.9 & & -18.6 & \\
Heat to the Copper (kJ) & -53.3 & -220.9 & & -10.4 & \\
Copper $\Delta$ H from 64 K to 76 K (J g $\left.{ }^{-1}\right)$ & 2.5 & 2.5 & & 2.5 & \\
Copper Mass Needed with Cooling (kg) & 0 & 0 & & 0 & \\
Copper Mass Needed w/o Cooling (kg) & 51.8 & 34.6 & & 43.2 & \\
\hline \hline
\end{tabular}

Figure 11 shows how the helium boil off gas can be used to cool the shield around the HTS leads. One can make the helium boil off gas line part of the magnet cool down circuit, provided there is a separate helium relief path from the bottom of the magnet helium tank. This relief path can be the helium feed line that is used to feed liquid helium to the magnet during the cool down. 


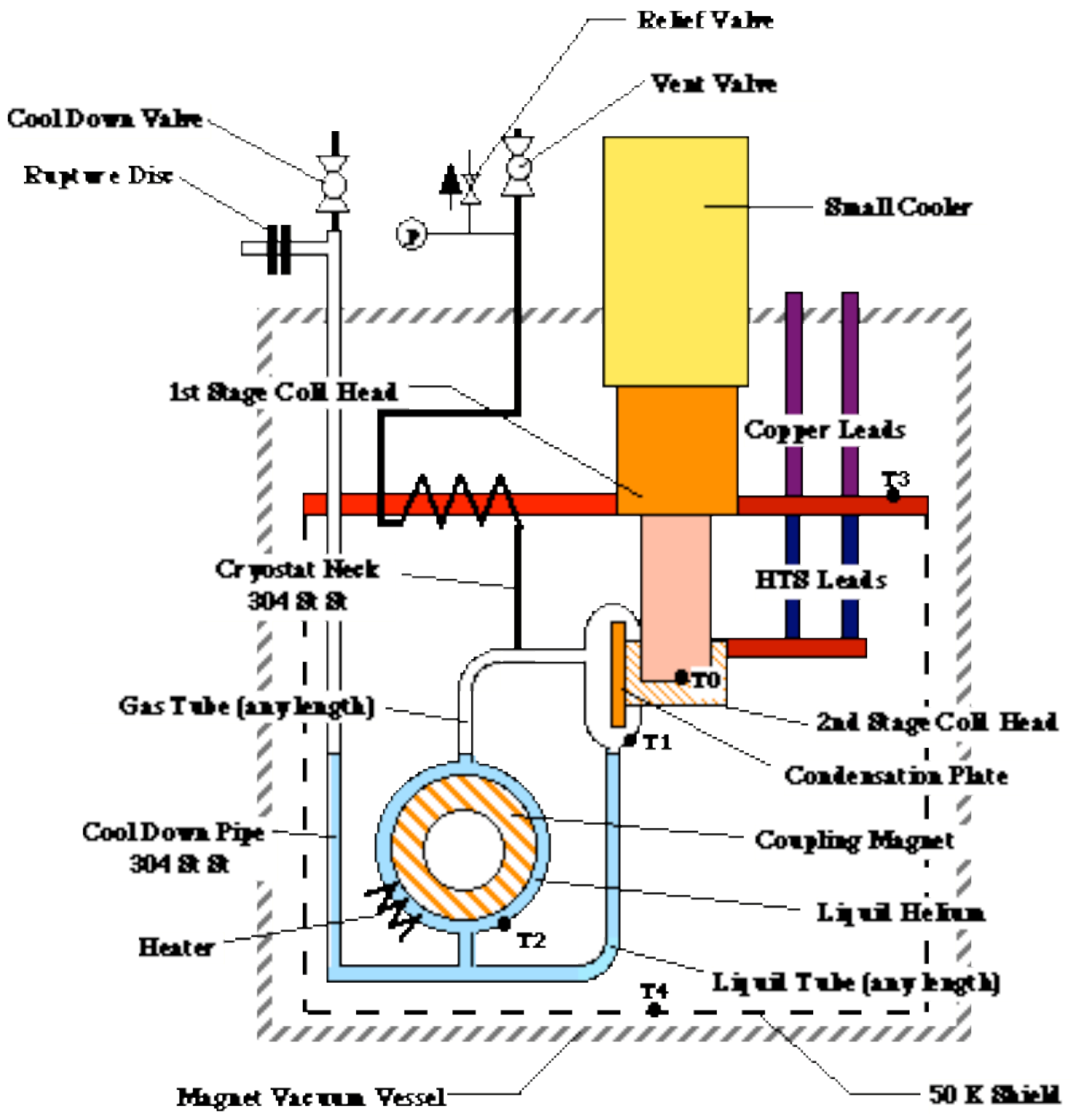

Figure 11. The MICE Coupling Magnet Cool Down and Vent System

(This system allows the helium boil off gas created by magnet AC losses during a rapid discharge to cool the thermal shield near the HTS leads.)

The liquid helium system shown in Figure 11 has normal operating pressure for the system of about $0.11 \mathrm{MPa}$ absolute. This pressure, which is slightly above atmospheric, will keep air from migrating in to the magnet helium system. The helium system pressure will be controlled by using a heater attached to the magnet cold mass.

During a magnet charge, when the cooler is running, the helium pressure rises as AC loss energy is put into the helium. The relief valve is set at a pressure of $\sim 0.14 \mathrm{MPa}$. (The temperature is $4.6 \mathrm{~K}$ at this pressure.) When the pressure reaches the relief pressure, helium is boiled from the system. The system shown in Figure 8 will allow the boil off helium due to AC losses during a rapid discharge to cool the shield around the HTS leads, provided the system vents to the atmosphere. The helium vent valve shown in Figure 8 must open when there is a power outage. This boils off additional helium due to the change in pressure. This helium gas is added to the gas generated by AC losses. 
Table 5 is quite conservative in the calculation of the amount of heat deposited into the shield from the leads and other sources. The heat flow into the shield is based on the copper leads operating at their optimum current. When the leads carry no current, the heat flow down the leads is around 50 percent the heat load down the leads when they operate at their optimum current. The average heat load down the copper leads is about 75 percent of the heat flow down the leads at their design current (see Table 5).

\section{AC Losses and Temperature Distribution in the MICE Coupling Magnet}

The remaining issue that one has to deal with is the temperature distribution in the magnet during a magnet charge or discharge. The temperature distribution within the magnet was calculated for the coupling solenoid by ICST. The ICST calculations are compared to calculations that were made at Oxford University in 2004 [4]. The ICST calculations can be scaled for the other two types of MICE magnets.

Table 6 compares the calculations of the temperature difference between the hot-spot temperature and the temperature of the surface cooled by helium at $4.3 \mathrm{~K} \mathrm{[4].} \mathrm{The}$ calculations were done by hand and by using ANSYS. The cases covered had radiation heat transfer $\mathrm{Q}_{\mathrm{R}}$ on the outer surface of cold mass and uniform heat generation $\mathrm{Q}_{\mathrm{G}}$ within the coil. Heat transfer from the coil was either on three surfaces (the inner surface and the two ends) or four surfaces (the inner and outer surface and the two ends)

Table 6. The Temperature Difference in the Coupling Coil Package $\Delta \mathrm{T}$ as a Function of the Type of Calculation, the Thermal Radiation on the Cold Mass Surface $\mathrm{Q}_{R}$, The Heat Generated per unit Coil Volume $Q_{G}$ and the Number of Coil Surfaces Cooled $N_{S}$ (Note the volume of the coil is $0.144 \mathrm{~m}^{3}$.)

\begin{tabular}{cccccc}
\hline \hline Case & Type & $\begin{array}{c}\mathrm{Q}_{\mathrm{R}} \\
\left(\mathrm{W} \mathrm{m}^{-2}\right)\end{array}$ & $\begin{array}{c}\mathrm{Q}_{\mathrm{G}} \\
\left(\mathrm{W} \mathrm{m}^{3}\right)\end{array}$ & $\mathrm{N}_{\mathrm{S}}$ & $\begin{array}{c}\Delta \mathrm{T} \\
(\mathrm{K})\end{array}$ \\
\hline 1 & Hand & 1.0 & 0 & 3 & 0.301 \\
2 & Hand & 0.2 & 0 & 3 & 0.060 \\
3 & Hand & 1.0 & 100 & 3 & 3.301 \\
4 & Hand & 1.0 & 100 & 4 & 1.708 \\
5 & ANSYS & 1.0 & 0 & 3 & 0.268 \\
6 & ANSYS & 1.0 & 100 & 3 & 2.569 \\
7 & ANSYS & 1.0 & 20 & 3 & 1.038 \\
8 & ANSYS & 1.0 & 100 & 4 & 1.563 \\
9 & ANSYS & 1.0 & 20 & 4 & 0.456 \\
\hline \hline
\end{tabular}

Table 6 compares the calculations of the temperature drop from the coil hot spot to the helium cooling at $4.3 \mathrm{~K}$. These calculations were made by hand and by the use of ANSYS in reference [4]. If one compares the $\Delta \mathrm{T}$ in Case 1 with Case 5, the agreement was reasonably good. Since the temperature difference calculated using ANSYS included the non-linear thermal conductivity and the hand calculation used the thermal conductivity at $4.3 \mathrm{~K}$, the calculated $\Delta \mathrm{T}$ in the ANSYS case was lower. A similar comparison can be made between Case 3 and Case 6 and between Case 4 and Case 8 .

Figure 12 shows the temperature distribution within the coupling magnet when 1.5 W of heat is applied as radiation to the cold mass surface and as heat flow into the magnet through the cold mass supports. The heat flow in Figure 12 is equivalent to a radiation heat load of $0.309 \mathrm{~W} \mathrm{~m}^{-2}$ applied over an area of $4.855 \mathrm{~m}^{2}$. The cooling tubes are at $4.27 \mathrm{~K}$ and the highest temperature within the cold mass is $4.344 \mathrm{~K}$. 


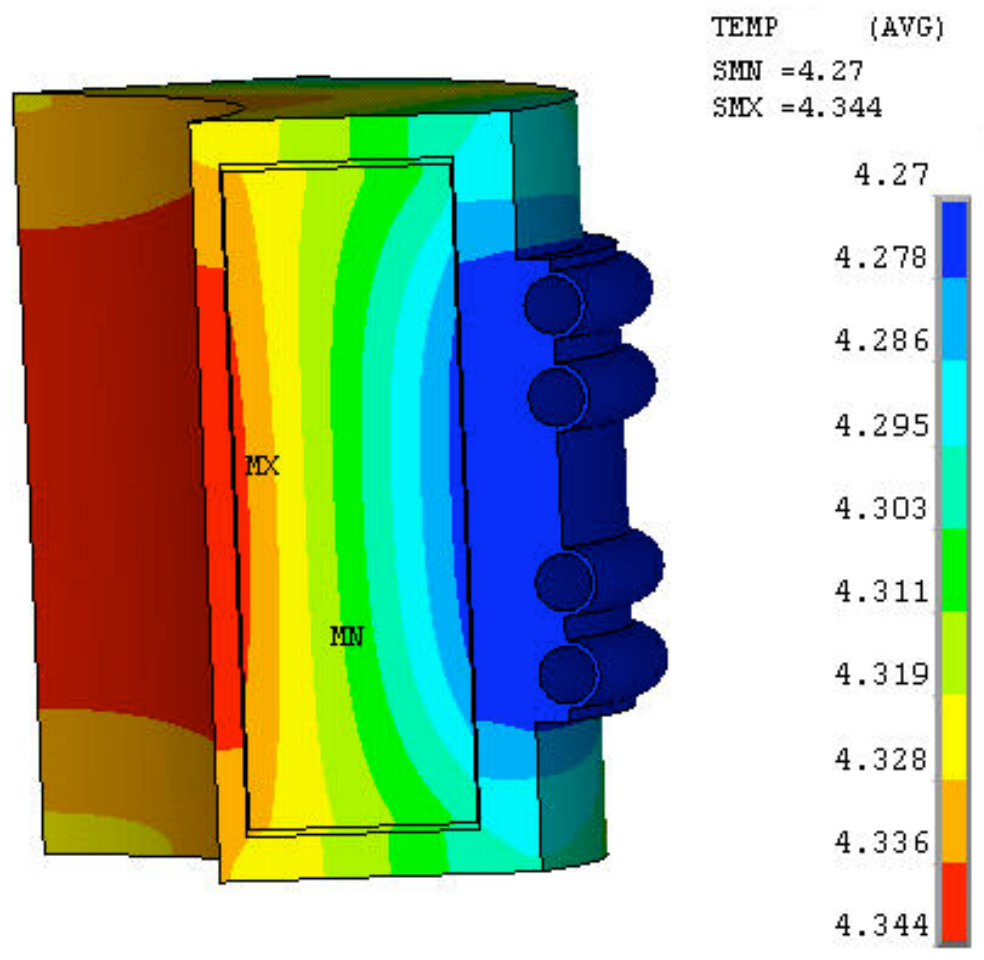

a) A 2 Dimensional Coupling Magnet Cross-section

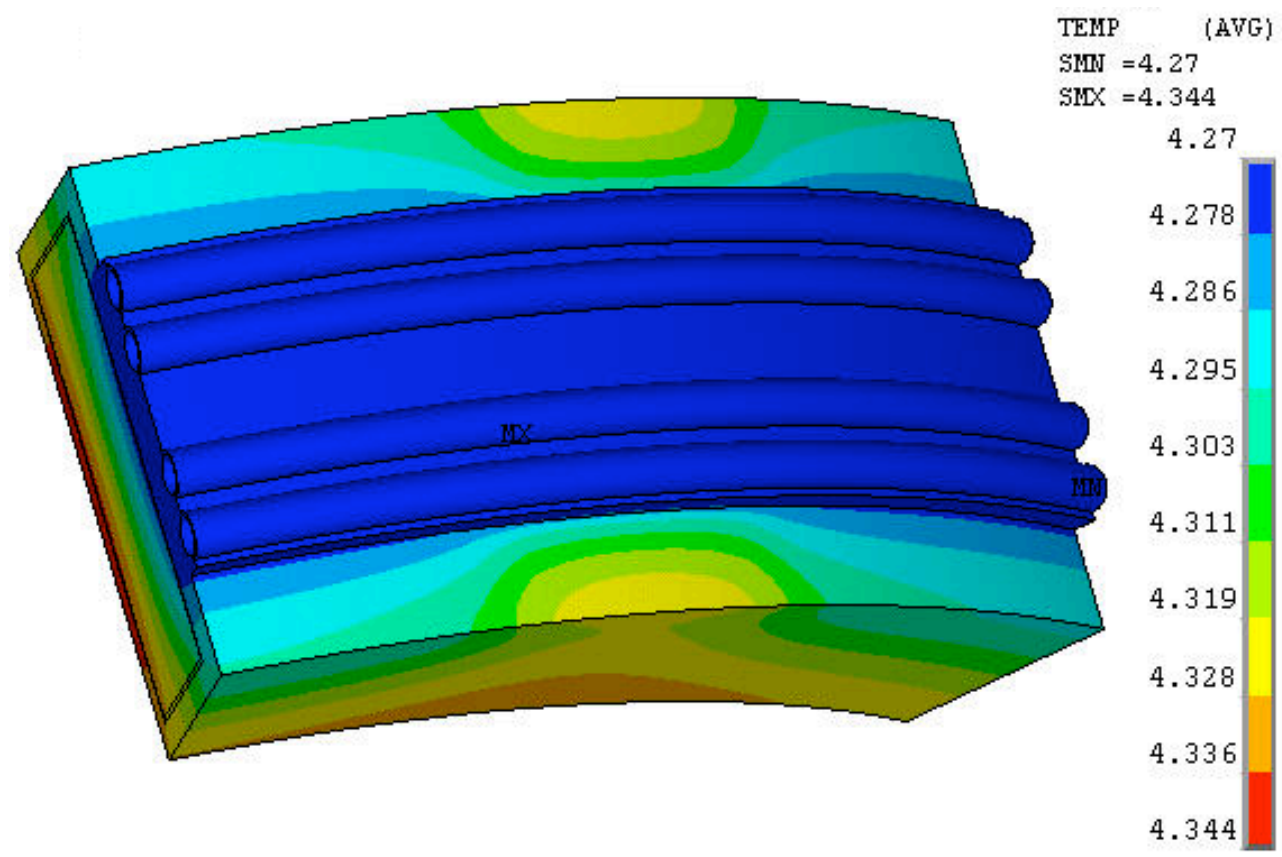

b) Magnet Section Near a Cold Mass Support Connection to the Cold Mass

Figure 12. The Temperature Distribution within the Coupling Magnet Cold Mass with Cooling at $4.27 \mathrm{~K}$ in the Cooling Tubes that are attached to the Coil Cold Mass Outer Case. (Note; There is no AC loss heating in the coil or the magnet mandrel. Note the high temperature point at $4.344 \mathrm{~K}$ occurs at the inner boundary of the magnet coil where the magnetic field is the highest.) The figure was created at ICST. 
The calculated temperature drop using ANSYS from the high temperature point (also the high field point) in the coupling magnet versus AC loss is shown in Figure 13. The calculated temperature drop at zero AC loss is the temperature drop due to $1.5 \mathrm{~W}$ of heat entering the magnet as thermal radiation $\mathrm{Q}_{\mathrm{R}}=0.309 \mathrm{~W} \mathrm{~m}^{-2}$ over a surface area of $4.855 \mathrm{~m}^{2}$ on the surface of the magnet (see Figure 12).

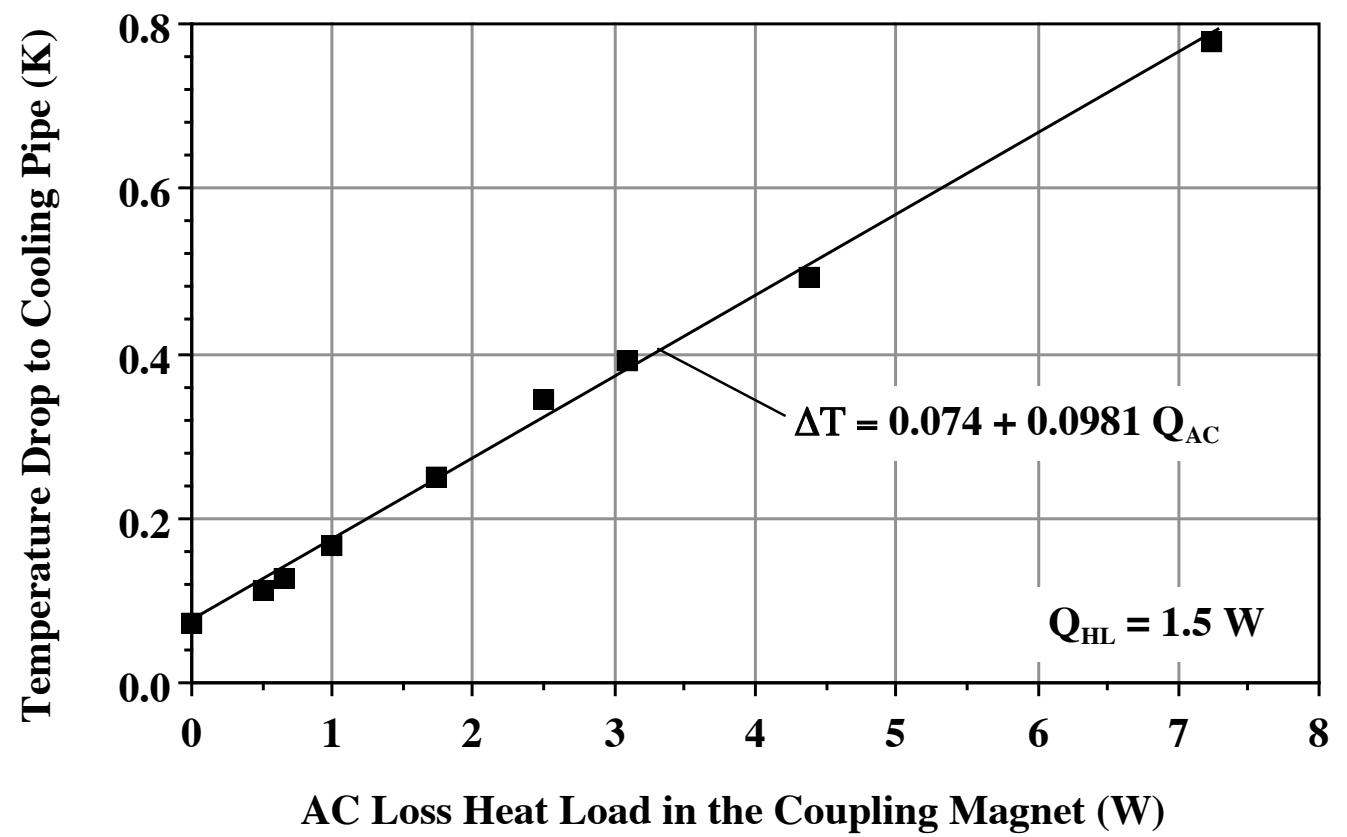

Figure 13. The Temperature Drop between the High Temperature Point in the MICE Coupling Magnet and the inside Surface of the Helium Cooling Tube, which is at $4.27 \mathrm{~K}$

The temperature drop between the magnet hot spot and the cooling in the coupling magnet can be calculated using the following expression;

$$
\Delta T=\Delta T_{H L}+\Delta T_{A C}
$$

where $\Delta \mathrm{T}$ is the total temperature drop in the magnet; $\Delta \mathrm{T}_{\mathrm{HL}}$ is the temperature drop due to heat leaks into the cold mass from the outside world; and $\Delta \mathrm{T}_{\mathrm{AC}}$ is the temperature drop due to $\mathrm{AC}$ losses in the coupling magnet coil and the magnet mandrel. $\left(\Delta \mathrm{T}_{\mathrm{AC}}\right.$ is dominated by $\mathrm{AC}$ losses in the magnet coil.) The values of $\Delta \mathrm{T}_{\mathrm{HL}}$ and $\Delta \mathrm{T}_{\mathrm{AC}}$ can be estimated for the coupling magnet using the following expressions;

$$
\begin{aligned}
\Delta T_{H L} & =0.049 Q_{H L} \\
\Delta T_{A C} & =0.098 Q_{A C}
\end{aligned}
$$

where $\mathrm{Q}_{\mathrm{HL}}$ is the sum of the heat leak due to radiation through the MLI, the heat leak down the cold mass supports and the heat leak down the leads. $\mathrm{Q}_{\mathrm{AC}}$ is the heat generated in the coupling magnet and its mandrel due to AC losses 
The temperature drop between the coil hot-spot and the cooling tube is $0.074 \mathrm{~K}$. The average heat flux on the surface of the mandrel was $0.309 \mathrm{~W} \mathrm{~m}^{-2}$. When one compares the ICST calculations with the Oxford calculation (by hand and using ANSYS) one sees that there is some agreement between the Oxford calculation $\left(0.301 \mathrm{~K} / \mathrm{Wm}^{2}\right.$ and 0.268 $\left.\mathrm{K} / \mathrm{Wm}^{2}\right)$ and the ICST calculation of $\left(0.239 \mathrm{~K} / \mathrm{Wm}^{2}\right)$. The ICST coupling magnet design has more 6061 aluminum and it is also thinner. The helium temperature is $4.32 \mathrm{~K}$.

Table 7 shows heat flow into the cold mass, the magnet AC loss, the total heat flow into the magnet, the magnet hot spot temperature, and the magnet temperature margin as a function of time while charging the coupling magnet in 13860 seconds to $210 \mathrm{~A}$ (the coupling magnet current for $\mathrm{p}=240 \mathrm{MeV} / \mathrm{c}$ and $\mathrm{b}=420 \mathrm{~mm}$ ) from zero current. Table 8 shows heat flow into the cold mass, the magnet AC loss, the total heat flow into the magnet, the magnet hot spot temperature, and the magnet temperature margin as a function of time while discharging the coupling magnet in 5400 seconds from $210 \mathrm{~A}$.

Table 7. The Heat Flow into the Magnet, the AC Losses, the Magnet Spot Temperature and the Worstcase Magnet Temperature Margin as a Function of Time During a 13860 second Magnet Charge

\begin{tabular}{cccccc}
\hline \hline $\begin{array}{c}\text { Time } \\
(\mathbf{s e c})\end{array}$ & $\begin{array}{c}\text { Heat Leak } \\
(\mathbf{W})\end{array}$ & $\begin{array}{c}\text { AC Loss } \\
(\mathbf{W})\end{array}$ & $\begin{array}{c}\text { Total Heat } \\
(\mathbf{W})\end{array}$ & $\begin{array}{c}\text { Hot Spot T } \\
(\mathbf{K})\end{array}$ & $\begin{array}{c}\text { T Margin } \\
(\mathbf{K})\end{array}$ \\
\hline 0 & 1.50 & 0 & 1.500 & 4.39 & $\sim 5.0$ \\
693 & 1.50 & 1.778 & 3.278 & 4.64 & $\sim 4.4$ \\
2079 & 1.50 & 1.168 & 2.668 & 4.58 & $\sim 4.0$ \\
3465 & 1.50 & 0.928 & 2.428 & 4.54 & $\sim 3.6$ \\
4851 & 1.50 & 0.808 & 2.308 & 4.53 & $\sim 3.2$ \\
6237 & 1.50 & 0.698 & 2.198 & 4.52 & $\sim 2.8$ \\
7623 & 1.50 & 0.628 & 2.168 & 4.52 & $\sim 2.4$ \\
9009 & 1.50 & 0.568 & 2.068 & 4.51 & $\sim 2.0$ \\
10395 & 1.50 & 0.518 & 2.018 & 4.50 & $\sim 1.6$ \\
11781 & 1.50 & 0.478 & 1.978 & 4.50 & $\sim 1.2$ \\
13167 & 1.50 & 0.448 & 1.948 & 4.49 & $\sim 0.8$ \\
13860 & 1.50 & 0.433 & 1.933 & 4.48 & $\sim 0.5$ \\
\hline \hline
\end{tabular}

Table 8. The Heat Flow into the Magnet, the AC Losses, the Magnet Spot Temperature and the Worstcase Magnet Temperature Margin as a Function of Time During a 5400 second Magnet Discharge

\begin{tabular}{cccccc}
\hline \hline $\begin{array}{c}\text { Time } \\
(\mathbf{s e c})\end{array}$ & $\begin{array}{c}\text { Heat Leak } \\
(\mathbf{W})\end{array}$ & $\begin{array}{c}\text { AC Loss } \\
(\mathbf{W})\end{array}$ & $\begin{array}{c}\text { Total Heat } \\
(\mathbf{W})\end{array}$ & $\begin{array}{c}\text { Hot Spot T } \\
(\mathbf{K})\end{array}$ & $\begin{array}{c}\text { T Margin } \\
(\mathbf{K})\end{array}$ \\
\hline 0 & 1.50 & 0 & 1.500 & 4.39 & $\sim 0.6$ \\
270 & 1.50 & 1.264 & 2.764 & 4.59 & $\sim 0.7$ \\
810 & 1.50 & 1.344 & 2.844 & 4.61 & $\sim 0.8$ \\
1350 & 1.50 & 1.444 & 2.944 & 4.62 & $\sim 0.9$ \\
1890 & 1.50 & 1.564 & 3.064 & 4.63 & $\sim 1.1$ \\
2430 & 1.50 & 1.714 & 3.214 & 4.64 & $\sim 1.5$ \\
2970 & 1.50 & 1.894 & 3.394 & 4.66 & $\sim 1.9$ \\
3510 & 1.50 & 2.174 & 3.674 & 4.70 & $\sim 2.3$ \\
4050 & 1.50 & 2.504 & 4.004 & 4.73 & $\sim 2.8$ \\
4590 & 1.50 & 3.104 & 4.604 & 4.78 & $\sim 3.4$ \\
5130 & 1.50 & 4.684 & 6.184 & 4.92 & $\sim 3.8$ \\
5400 & 1.50 & 6.904 & 8.404 & 5. & $\sim 4.1$ \\
\hline \hline
\end{tabular}


From Table 7, it is clear that worst-case temperature margin occurs at the end of a coupling magnet charge to its full current of $210 \mathrm{~A}$. Within ten or fifteen seconds, the magnet margin increases from $0.5 \mathrm{~K}$ to about $0.7 \mathrm{~K}$ [15]. The effect of penetration of the superconductor is not shown in Table 7. Since the superconductor is penetrated by the change of flux direction during the first 5000 seconds of the coil charging process (see Figure 4), the actual temperature margin will be a little larger in the beginning.

From Table 8, it is clear that worst-case temperature margin occurs at the beginning of a coupling magnet is discharge from its full current of $210 \mathrm{~A}$. The effect of penetration of the superconductor is not shown in Table 8. Since the superconductor is penetrated by the change of flux direction during the first 900 seconds (see Figure 5), the actual temperature margin will be a little larger during the early phases of the magnet discharging process. Ten to fifteen seconds after the magnet discharge is finished, the magnet temperature margin jumps to about $5 \mathrm{~K}$ (not that it really matters).

\section{AC Losses and Temperature Distribution in the Other MICE Magnets}

\section{a) Temperature Margin in the Focusing Magnets}

Table 9 compares the calculations of the temperature difference between the hot-spot temperature and the temperature of the surface cooled by helium at $4.3 \mathrm{~K}$ for the focusing magnet [4]. The calculations were done by hand and by using ANSYS. The cases covered have radiation heat transfer $Q_{R}$ on the outer surface area of cold mass $\left(Q_{R}=0.2\right.$ and $\left.1.0 \mathrm{~W} \mathrm{~m}^{-2}\right)$ and uniform heat generation $\mathrm{Q}_{\mathrm{G}}\left(\mathrm{Q}_{\mathrm{G}}=0,20\right.$, and $\left.100 \mathrm{~W} \mathrm{~m}^{-3}\right)$ within the coil. Heat transfer from the coil was either on three surfaces $\mathrm{N}_{\mathrm{S}}=3$ (the inner surface and the two ends) or four surfaces $\mathrm{N}_{\mathrm{S}}=4$ (the inner and outer surface and the two ends).

Table 9. The Temperature Difference in the Focusing Coil Package $\Delta \mathrm{T}$ as a Function of the Type of Calculation, the Thermal Radiation on the Cold Mass Surface $\mathrm{Q}_{R}$, The Heat Generated per unit Coil

Volume $\mathrm{Q}_{\mathrm{G}}$ and the Number of Coil Surfaces Cooled $\mathrm{N}_{\mathrm{S}}$ (Note the volume of each coil is $0.0338 \mathrm{~m}^{3}$.)

\begin{tabular}{|c|c|c|c|c|c|}
\hline Case & Type & $\begin{array}{c}\mathrm{Q}_{\mathrm{R}} \\
\left(\mathrm{W} \mathrm{m}^{-2}\right)\end{array}$ & $\begin{array}{c}\mathrm{Q}_{\mathrm{G}} \\
\left(\mathrm{W} \mathrm{m}^{3}\right)\end{array}$ & $\mathrm{N}_{\mathrm{S}}$ & $\begin{array}{l}\Delta \mathrm{T} \\
(\mathrm{K})\end{array}$ \\
\hline 1 & Hand & 1.0 & 0 & 3 & 0.196 \\
\hline 2 & Hand & 0.2 & 0 & 3 & 0.039 \\
\hline 3 & ANSYS & 1.0 & 0 & 3 & 0.125 \\
\hline 4 & ANSYS & 1.0 & 20 & 3 & 0.584 \\
\hline 5 & ANSYS & 1.0 & 100 & 3 & 2.209 \\
\hline 6 & ANSYS & 1.0 & 20 & 4 & 0.236 \\
\hline 7 & ANSYS & 1.0 & 100 & 4 & 0.815 \\
\hline
\end{tabular}

The hand calculation of the $\Delta \mathrm{T}$ is pessimistic compared to the calculation using ANSYS. The contribution of heat transfer through the coil was neglected in the hand calculations shown in cases 1 and 2. Heat transfer through the coil was included in the ANSYS case (case 3).

Cases 4 and 5 with heat being transferred from the coil using three of the coil surfaces are shown in Figure 13, which comes from reference 4. In cases 4 and 5 there is no contact between the coil outer surface and liquid helium. Cases 6 and 7 with heat being transferred from the coil using four of the coil surfaces are shown in Figure 14, which comes from reference 4 . In cases 6 and 7 there is contact between the coil outer surface and liquid helium. The focusing coil will be cooled on all four surfaces. 


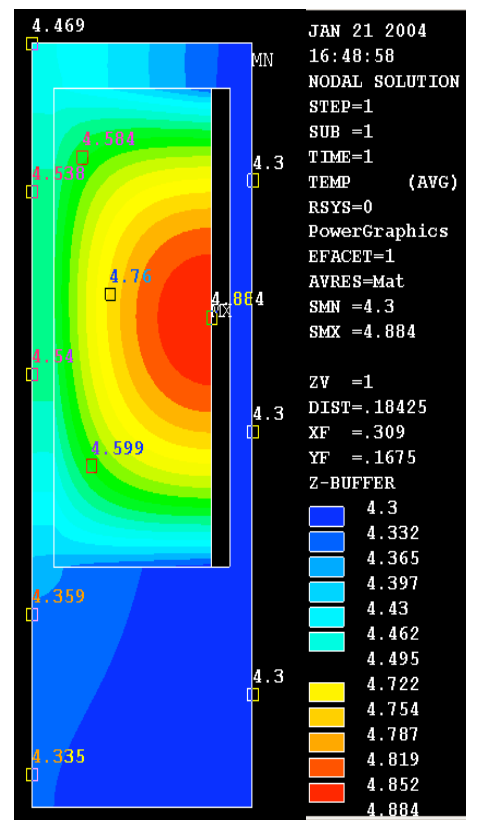

$\mathrm{Q}_{\mathrm{G}}=20 \mathrm{~W} \mathrm{~m}^{-3}, \Delta \mathrm{T}=\mathbf{0 . 5 8 4} \mathrm{K}$

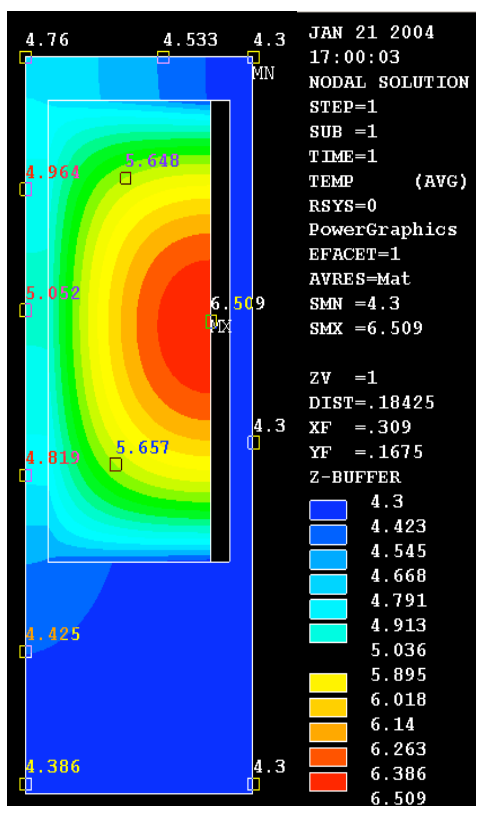

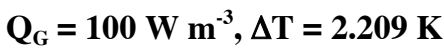

Figure 14. The temperature Distribution within the Focusing Coil Package Calculated with ANSYS The heat flux on the inner cylindrical surface and ends is $1 \mathrm{~W} \mathrm{~m}^{-2}$; the outer cylindrical surface is at $4.3 \mathrm{~K}$. Heat is generated in the coil $\left(\mathrm{Q}_{\mathrm{G}}=20\right.$ and $\left.100 \mathrm{~W} \mathrm{~m}^{-3}\right)$ and there is no heat flow on the outside of the coil.

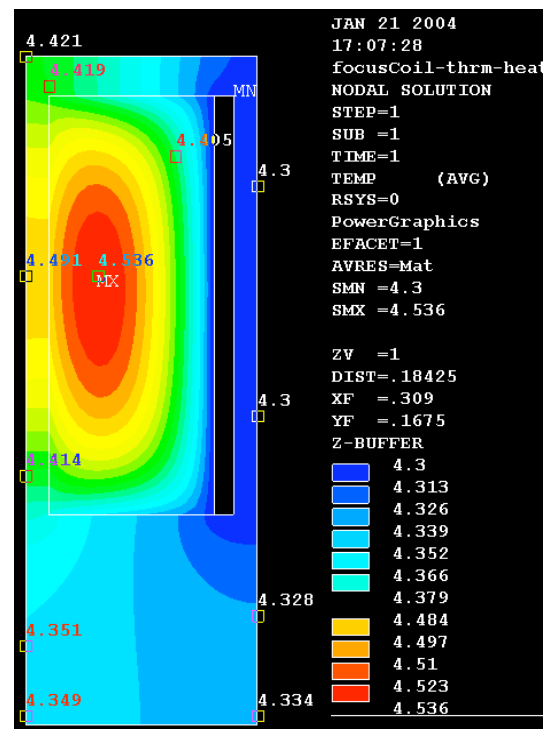

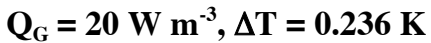

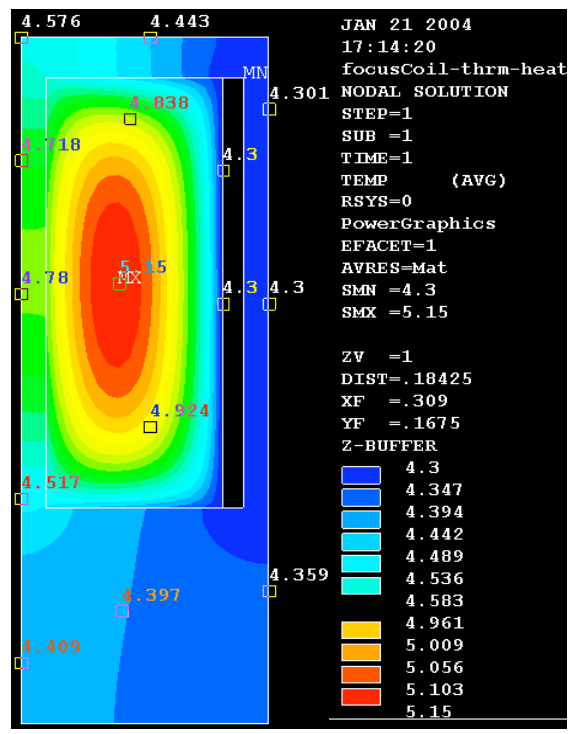

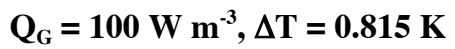

Figure 15. The temperature Distribution within the Focusing Coil Package Calculated with ANSYS The heat flux on the inner cylindrical surface and ends is $1 \mathrm{~W} \mathrm{~m}^{-2}$; the outer cylindrical surface is at $4.3 \mathrm{~K}$.

Heat is generated in the coil $\left(\mathrm{Q}_{\mathrm{G}}=20\right.$ and $\left.100 \mathrm{~W} \mathrm{~m}^{-3}\right)$ and the coil outer surface is cooled to $4.3 \mathrm{~K}$.

It is interesting to note that the temperature of the focusing magnet at its high field point in the $\mathrm{Q}_{\mathrm{R}}=100 \mathrm{~W} \mathrm{~m} \mathrm{~m}^{-3}$ case is about $5.04 \mathrm{~K}$ in Figure 14 . The highest temperature in the coil is on the outside of the coil. The temperature of the focusing magnet at its high field point in the $\mathrm{Q}_{\mathrm{G}}=100 \mathrm{~W} \mathrm{~m}^{-3}$ case is about $4.75 \mathrm{~K}$ in Figure 15 . The highest temperature in the coil is in the middle of the coil. 
Note that $\mathrm{Q}_{\mathrm{G}}=100 \mathrm{~W} \mathrm{~m}^{-3}$ would result in an AC loss for the entire focusing magnet of $6.76 \mathrm{~W}$. The estimated focusing magnet AC loss shown in Figure 6 is about $1.7 \mathrm{~W}$ per magnet at the beginning of the charging process (when superconductor penetration is neglected) during a $9 \mathrm{~V}$ charge of the three focusing magnets in series. At the end of the $9 \mathrm{~V}$ charge of three magnets, the AC loss per magnet is less than $0.4 \mathrm{~W}$. During a magnet charge with all four surfaces of the magnet coils cooled, the peak temperature rise at the magnet high field point in the magnet is expected to be less than $0.07 \mathrm{~K}$. The expected temperature margin is about $0.5 \mathrm{~K}$ when the helium is at $4.3 \mathrm{~K}$. Experience with the Lab $\mathrm{G}$ solenoid showed that the magnet could be charged to full current with $9 \mathrm{~V}$ across a single magnet. The temperature rise at the high field point was about $0.2 \mathrm{~K}$.

When three focusing magnets are rapidly discharged through a varistor in $3600 \mathrm{~s}$, the peak AC loss per magnet at the beginning of the discharge is about $1 \mathrm{~W}$ (when flux penetration of the superconductor is neglected). The temperature rise is expected to be of the order of $0.17 \mathrm{~K}$. When the helium cooling is at $4.3 \mathrm{~K}$, the worst-case temperature margin during a rapid discharge is expected to be about $0.4 \mathrm{~K}$ [16]. If the flux penetration into the superconductor is considered, the temperature margin increases.

\section{b) Temperature Margin in the Tracker Magnets}

The temperature margin in all of the tracker magnet coils is larger than any of the other magnets in the MICE cooling channel. The worst-case temperature margin for any of the tracker magnet coils is about $1.3 \mathrm{~K}$. The tracker magnet coils are well cooled with a reservoir of liquid helium on the outside of all of the coils. Three of the four coils are shorter and thinner than the MICE focusing coils. The AC losses for the entire magnet are lower than that of the coupling magnet. The AC losses are a little larger than the AC losses for the focusing magnet. The AC losses per unit coil volume are lower than either the coupling magnet or the focusing magnet. The $\Delta \mathrm{T}$ within the tracker magnet is expected to be lower than either of the other MICE magnets.

The most important coil in the tracker magnet may be the 1.314-meter long center coil. To the first order, all of the heat from the mandrel and the coil in the magnet center coil must be transferred through the coil and the aluminum banding around the outside of the coil. The largest $\Delta \mathrm{T}$ in the tracker magnet is probably in the long center coil.

The temperature drop between the tracker mandrel and the helium bath on the outside coil banding $\Delta \mathrm{T}_{\mathrm{C}}$ can be calculated using the following expression;

$$
\Delta T_{C}=\Delta T_{1}+\Delta T_{2}+\Delta T_{3}+\Delta T_{4}
$$

where $\Delta \mathrm{T}_{1}$ is the temperature drop from the tracker magnet mandrel to the inside if the aluminum banding due to heat generated in the mandrel and heat deposited on the inside of the mandrel. $\Delta \mathrm{T}_{2}$ is the temperature drop due to heat generated in the magnet coil; $\Delta \mathrm{T}_{3}$ is the temperature drop across the banding layer; and $\Delta \mathrm{T}_{4}$ is the temperature drop across the magnet coil ground plane insulation.

The three temperature drops $\Delta \mathrm{T}_{1}, \Delta \mathrm{T}_{2}, \Delta \mathrm{T}_{3}$ and $\Delta \mathrm{T}_{4}$ can be estimated using the following expressions;

$$
\Delta T_{1} \approx \frac{Q_{1}\left(R_{2}-R_{1}\right)}{k_{c}\left(R_{2}+R_{1}\right) \pi}
$$




$$
\begin{aligned}
& \Delta T_{2} \approx \frac{Q_{G}\left(R_{2}-R_{1}\right)^{2}}{2 k_{c}}, \\
& \Delta T_{3}=\frac{\left(Q_{1}+Q_{2}\right)\left(R_{3}-R_{2}\right)}{k_{b}\left(R_{3}+R_{2}\right) \pi},
\end{aligned}
$$

and

$$
\Delta T_{4}=\frac{Q_{1} t_{i}}{2 k_{i} R_{1} \pi}+\frac{\left(Q_{1}+Q_{2}\right) t_{i}}{2 k_{i} R_{2} \pi}
$$

where $R_{0}$ is the inner radius of the mandrel; $R_{1}$ is the inner radius of the coil; $R_{2}$ is the outer radius of the coil; and $R_{3}$ is the outer radius of the banding. $k_{c}$ is the thermal conductivity of the coil package in the redial direction; $\mathrm{k}_{\mathrm{b}}$ is the thermal conductivity of the banding package; and $\mathrm{k}_{\mathrm{i}}$ is the thermal conductivity of the ground plane insulation. $\mathrm{Q}_{1}$ is the heat generated in the mandrel due to AC loss and heat transferred to the mandrel by radiation on the inner surface. $\mathrm{Q}_{2}$ is the heat generated within the coil due to $\mathrm{AC}$ loss. $\mathrm{Q}_{\mathrm{G}}$ is the heat per unit volume generated in the coil due $\mathrm{AC}$ loss.

The heat terms $\mathrm{Q}_{1}, \mathrm{Q}_{2}$, and $\mathrm{Q}_{\mathrm{G}}$ can be calculated using the following expressions;

$$
\begin{aligned}
& Q_{1} \approx 2 \pi R_{0} Q_{R}+\frac{V_{d}^{2}}{N_{c}^{2}} \frac{\left(R_{1}-R_{0}\right)}{\rho_{M}\left(R_{1}+R_{0}\right) \pi}, \\
& Q_{2} \approx Q_{G} \pi\left(R_{2}^{2}-R_{1}^{2}\right),
\end{aligned}
$$

and

$$
Q_{G}=\frac{P_{A C}}{V_{M C}}
$$

where

$$
Q_{R}=\frac{Q_{T}}{A_{C M}}
$$

where $V_{d}$ is the discharge voltage across the tracker solenoid spectrometer coils; $N_{C}$ is the number turns in the three coil spectrometer magnet; $\rho_{\mathrm{M}}$ mandrel material resistivity; $\mathrm{P}_{\mathrm{AC}}$ is the $\mathrm{AC}$ loss heating for the entire magnet; $\mathrm{V}_{\mathrm{MC}}$ is the volume of the magnet coils; $\mathrm{Q}_{\mathrm{TR}}$ is the total heat flow into the magnet cold mass due to radiation and from the cold mass supports; and $\mathrm{A}_{\mathrm{CM}}$ is the total surface area of the cold mass.

It is useful to look at some assumptions. First, we assume that the total heat entering the cold mass by radiation and conduction is $1.5 \mathrm{~W}$. The area of the cold mass is $9.43 \mathrm{~m}^{2}$. As a result, $\mathrm{Q}_{\mathrm{R}}=0.159 \mathrm{~W} \mathrm{~m}^{-2}$. The peak AC loss in the magnet coil is $5.3 \mathrm{~W}$. The coil volume is $0.0978 \mathrm{~m}^{3}$. As a result $\mathrm{Q}_{\mathrm{G}}=54.4 \mathrm{~W} \mathrm{~m}^{-3}$. 
The following constants can be used in the heat transfer equations for the tracker magnet when its temperature is between $4.3 \mathrm{~K}$ and $4.5 \mathrm{~K}$;

$$
\begin{aligned}
& R_{0}=0.245 \mathrm{~m} \\
& R_{1}=0.258 \mathrm{~m} \\
& R_{2}=0.2796 \mathrm{~m} \\
& R_{3}=0.2926 \mathrm{~m} \\
& t_{i}=0.001 \mathrm{~m}
\end{aligned}
$$

$$
\begin{aligned}
& k_{c}=0.068 \mathrm{~W} \mathrm{~m}^{-1} \mathrm{~K}^{-1} \\
& k_{b}=0.252 \mathrm{~W} \mathrm{~m}^{-1} \mathrm{~K}^{-1} \\
& k_{i}=0.023 \mathrm{~W} \mathrm{~m}^{-1} \mathrm{~K}^{-1} \\
& V_{D}=11.6 \mathrm{~V} \\
& N_{C}=23336 \\
& \rho_{M}=1.5 \times 10^{-8} \Omega \mathrm{m}
\end{aligned}
$$

Using the constants given above one can calculate the values of $\mathrm{Q}_{1}$ and $\mathrm{Q}_{2}$. Thus we find that $\mathrm{Q}_{1}=0.381 \mathrm{~W}$, and $\mathrm{Q}_{2}=2.000 \mathrm{~W}$. Once one knows $\mathrm{Q}_{1}$ and $\mathrm{Q}_{2}$, one can calculate the values of $\Delta \mathrm{T}_{1}, \Delta \mathrm{T}_{2}, \Delta \mathrm{T}_{3}$ and $\Delta \mathrm{T}_{4}$. When on applies equations $30 \mathrm{a}$ through $30 \mathrm{~d}$, one gets the following temperature drops; $\Delta \mathrm{T}_{1}=0.072 \mathrm{~K}, \Delta \mathrm{T}_{2}=0.186 \mathrm{~K}, \Delta \mathrm{T}_{3}=0.069 \mathrm{~K}$, and $\Delta \mathrm{T}_{4}=0.069 \mathrm{~K}$. Thus the worst-case total temperature drop in the spectrometer coil of the tracker magnet $\Delta \mathrm{T}_{\mathrm{C}}=0.396 \mathrm{~K}$. The worst-case temperature drop is small compared to the temperature margin in any of the tracker magnet coils [17].

\section{Some Concluding Comments}

The AC losses were calculated for all three of the MICE magnets. The worst-case AC losses for the coupling magnet occur at the end of a $5400 \mathrm{~s}$ rapid discharge. The peak $\mathrm{AC}$ loss in the coupling magnet is about $7.0 \mathrm{~W}$. During a rapid coupling magnet discharge, $13.1 \mathrm{~kJ}$ of energy is released into the helium around the magnet. This energy is enough to boil away 5.3 liters of liquid helium. The worst-case AC losses for the focusing magnet occur at the end of a $3600 \mathrm{~s}$ rapid discharge. The peak AC loss in the focusing magnet is about $5.3 \mathrm{~W}$. During a rapid focusing magnet discharge, $5.5 \mathrm{~kJ}$ of energy is released into the helium around the magnet. This energy is enough to boil away 2.2 liters of liquid helium. The worst-case AC losses for the tracker magnet occur at the end of a $1800 \mathrm{~s}$ discharge. The peak AC loss in the tracker magnet is about $4.7 \mathrm{~W}$. During a rapid tracker magnet discharge, $5.3 \mathrm{~kJ}$ of energy is released into the helium around the magnet. This energy is enough to boil away 2.1 liters of liquid helium.

The rapid discharges assumed that the magnet was being discharged through a varistor. A more likely scenario is a magnet rapid discharge through a varistor and resistor in series. A rapid discharge through a combination of a varistor and resistor results in about same amount of AC loss energy being produced in the magnet. This means that the same amount of helium will be boiled away, but the helium will be boiled away over a longer period of time.

The design heat leak down the conduction-cooled magnet leads from $293 \mathrm{~K}$ to $60 \mathrm{~K}$ is about $0.090 \mathrm{~W} \mathrm{~A}^{-1}$ per lead pair when the leads operates at their design current. The heat leak down the conduction-cooled magnet leads from $293 \mathrm{~K}$ to $60 \mathrm{~K}$ when there is no current flowing through the lead is about half the heat leak down the leads when they carry their design current. Since the heat load on the first-stage of the magnet coolers is dominated by the heat load from the current leads, the cooler first-stage temperature will be lower when the leads carry less than their design current. 
It is clear that $\mathrm{AC}$ loss will produce enough heat in the MICE magnets to make it difficult to charge the magnets, while they are being cooled by their coolers alone. Since all three types of MICE magnets have liquid helium in contact with the magnet coils, it is reasonable to boil some of this helium while charging and discharging the magnets. The helium gas produced by boiling the liquid should be used to cool the area around the top of the HTS leads. This is particularly important during power failure, when there is no cooling available fro the cooler first-stage. The sensible heat available in the helium will help keep the top of the HTS leads cold during a rapid discharge of the magnet when the power fails. This is true for all three types of MICE magnets.

The AC losses in the coupling magnet cause the temperature to rise in the high field region of the magnet. Estimates of the temperature difference between the magnet hot spot and the liquid helium were made as a function of the AC losses in the magnet during a rapid discharge of 5400 seconds. The worst-case temperature drop reduces the temperature margin to $0.5 \mathrm{~K}$. The temperature margin is a little lower when the magnet is being charged than even during a rapid discharge of magnet. AC losses cause a temperature rise in the focusing magnet and the spectrometer magnet. The temperature margin of the focusing coil is reduced to about $0.4 \mathrm{~K}$ when there is a rapid discharge of 3600 seconds. The tracker solenoid has a worst-case temperature drop of about $0.4 \mathrm{~K}$. This temperature rise of the magnet high field point is less of an issue because the temperature margin in all of the tracker magnet coils is $1.3 \mathrm{~K}$ to $2.0 \mathrm{~K}$. The effect of a $0.4 \mathrm{~K}$ temperature rise is much less important for the tracker solenoid than the other MICE magnets.

Is AC loss a blessing or a curse? The answer is both. AC losses are a curse, because they limit the charging and discharging rate for the magnet, unless one is willing to boil away some liquid helium. For the coupling magnet, this means that a second cooler will be needed, if the magnet is to be charged while operating on the coolers. The charging and discharging of the focusing magnet and tracker magnet is less of a problem because more than one cooler is already being used. The tracker solenoid has a larger temperature margin than either the coupling magnet or the focusing magnet, so charging with just the coolers provided is an option.

The AC losses can be regarded as a blessing, provided the boil off helium gas from the liquid helium that is being boiled during charging and discharging the magnet is used to cool the upper end of the HTS leads. The AC losses are a definite blessing during a rapid magnet discharge that would have to occur in the event of a power failure at RAL. The helium boiled of during a power failure can and should be used to cool the upper end of the HTS current leads.

\section{Acknowledgements}

A portion of this work was supported by the Harbin Institute of Technology. A portion of this work was also supported by the Office of Science, United States Department of Energy, under DOE contract DE-AC02-05CH11231. DOE funding for the US Neutrino Factory and Muon Collider Collaboration is also gratefully acknowledged. 


\section{References}

[1] G. Gregoire, G. Ryckewaert, L. et al, "MICE and International Muon Ionization Cooling Experiment Technical Reference Document," http://hep04.phys.iit.edu/cooldemo/notes (October 2004)

[2] M. A. Green, "The Superconducting Solenoids for the MICE," LBNL Report LBNL51920, December. 2002, MICE Note 58, http://hep04.phys.iit.edu/cooldemo/notes

[3] M. A. Green, "The Cryogenic Refrigeration System for MICE," LBNL Report LBNL51751, November 2002 MICE Note 57, http://hep04.phys.iit.edu/cooldemo/notes

[4] M. A. Green and S. Q. Yang, "Heat Transfer into and within the $4.4 \mathrm{~K}$ Region and the 40 K Shields of the MICE Focusing and Coupling Magnets," Oxford University Physics Note 2, 28 April 2004, MICE Note 101, http://hep04.phys.iit.edu/cooldemo/notes

[5] M. A. Green, "Cooling the MICE Magnets using Small Cryogenic Coolers," Oxford University Physics Department Engineering Note 10, MICE Note 109, 10 September 2004, http://hep04.phys.iit.edu/cooldemo/notes

[6] T. Painter, National High Magnetic Field Laboratory, Florida State University, private communication concerning the performance of a PT-415 cooler.

[7] M. A. Green, "Liquefaction of Hydrogen and Helium using Small Coolers," LBNL-62458, 12 Feb. 2007, MICE Note 161, http://hep04.phys.iit.edu/cooldemo/notes

[8] M. A. Green, "The Effect of Magnetic Field on HTS Leads, What happens when the power fails at RAL?", MICE Note 162, http://hep04.phys.iit.edu/cooldemo/notes, LBNL62459, 14 February 2007

[9] Martin N. Wilson, Superconducting Magnets, Chapter 8, Oxford University Press, Oxford UK (1983)

[10] Martin N. Wilson, Superconducting Magnets, Chapter 11, Oxford University Press, Oxford UK (1983)

[11] A. M. Kadin, R. J. Webber, and D. Gupta, "Current Leads and Optimized Thermal Packaging for Superconducting Systems on Multistage Cryocoolers," IEEE Transactions on Applied Superconductivity 17, No. 2, p 915, (2007)

[12] M. A. Green and H. Witte, "Quench Protection and Magnet Power Supply Requirements For the MICE Focusing and Coupling Magnets," Oxford Physics Note 15, MICE Note 114, http://hep04.phys.iit.edu/cooldemo/notes LBNL-57580, (June 2005)

[13] M. A. Green, L. X. Jia, L. J. Addessi, J. R. Cullen Jr., A. J. Esper and R. E. Meier, "A Design Method for Multi-tube Gas Cooled Electrical Leads for the g-2 Superconducting Magnets," co-authored with Advances in Cryogenic Engineering 41, p 573, Plenum Press, New York (1996)

[14] R. G. Smits, et al, "Gas-Cooled Electrical Leads for Use on Forced Cooled Superconducting Magnets", Advances in Cryogenic Engineering 27, p 169, Plenum Press, New York, (1981)

[15] M. A. Green, L. Wang, G. Hang, L. X. Jia, D. Li, C. S. Liu, X. K. Liu, S. P. Virostek, and F. Y. Xu, "Engineering Design of the 1.5 meter Diameter Solenoid for the MICE RF Coupling Coil Modules," to be published in IEEE Transactions on Applied Superconductivity 18, No. 2

[16] S. Q. Yang, M. A. Green, G. Barr, U. Bravar, J. Cobb, W. Lau, R. S. Senanayake, and H. Witte, "The Mechanical and Thermal Design for the MICE Focusing Solenoid Magnet System," IEEE Transactions on Applied Superconductivity 15, No. 2, p 1259, (2005)

[17] M. A. Green, C. Y. Chen, T. Juang et al, "Design Parameters for the MICE Tracker Solenoid," IEEE Transactions on Applied Superconductivity 17, No. 2, p 1247, (2007) 


\section{DISCLAIMER}

This document was prepared as an account of work sponsored by the United States Government. While this document is believed to contain correct information, neither the United States Government nor any agency thereof, nor The Regents of the University of California, nor any of their employees, makes any warranty, express or implied, or assumes any legal responsibility for the accuracy, completeness, or usefulness of any information, apparatus, product, or process disclosed, or represents that its use would not infringe privately owned rights. Reference herein to any specific commercial product, process, or service by its trade name, trademark, manufacturer, or otherwise, does not necessarily constitute or imply its endorsement, recommendation, or favoring by the United States Government or any agency thereof, or The Regents of the University of California. The views and opinions of authors expressed herein do not necessarily state or reflect those of the United States Government or any agency thereof, or The Regents of the University of California. 